\title{
Präzisionsmedizin bei NSCLC im Zeitalter der Immuntherapie: Neue Biomarker zur Selektion der am besten geeigneten Therapie oder des am besten geeigneten Patienten
}

\section{Giovanni Rossia, b Alessandro Russo ${ }^{c}$ Marco Tagliamento $^{a}$ Alessandro Tuzi $^{d}$ Olga Nigro $^{d}$ Giacomo Vollome $^{a}$ Claudio Sini ${ }^{\mathrm{e}}$ Massimiliano Grassi ${ }^{\mathrm{a}}$ Maria Giovanna Dal Bello ${ }^{\mathrm{a}}$ Simona Coco ${ }^{a}$ Luca Longo $^{a}$ Lodovica Zullo ${ }^{a}$ Enrica Teresa Tanda ${ }^{f}$ Chiara Dellepiane $^{a}$ Paolo Pronzato ${ }^{a}$ Carlo Genova $^{a}$}

aLung Cancer Unit, Medical Oncology 2, IRCCS Ospedale Policlinico San Martino, Genua, Italien;

${ }^{b}$ Department of Medical, Surgical and Experimental Sciences, University of Sassari, Sassari, Italien;

${ }^{\mathrm{C}}$ Medical Oncology Unit, A.O. Papardo, Messina, Italien; ${ }^{\mathrm{d} U O}$ Oncologia, ASST Sette Laghi, Varese, Italien;

'Oncologia Medica e CPDO, ASSL di Olbia-ATS Sardegna, Olbia, Italien;

${ }^{f}$ Medical Oncology 2, IRCCS Ospedale Policlinico San Martino, Genua, Italien

\author{
Schlüsselwörter \\ NSCLC $\cdot$ Biomarker $\cdot$ Immuncheckpoint-Inhibitor . \\ Tumormutationslast · PD-L1 · T-Zell-Klonalität · POLE · PTEN- \\ Inaktivierung · STK11
}

\section{Zusammenfassung}

Durch die Weiterentwicklung der Therapien konnten die Ergebnisse von Patienten mit nicht kleinzelligem Lungenkarzinom (NSCLC) in den letzten Jahren deutlich verbessert werden. Während molekulare zielgerichtete Therapien bei bestimmten Subgruppen von Patienten wirksam sind, hatten insbesondere ImmuncheckpointInhibitoren (ICls) starken Einfluss auf die Outcomes von einem Großteil der Patienten mit nicht kleinzelligem Lungenkarzinom. Die Aktivität von Nivolumab wurde anfangs unabhängig von prädiktiven Biomarkern bewertet; in den nachfolgenden zulassungsrelevanten Studien mit anderen PD-1/PD-L1-Inhibitoren bei vorbehandelten Patienten mit fortgeschrittenem NSCLC (Atezolizumab in der OAK-Studie und Pembrolizumab in der KEYNOTE-010-Studie)

wurde dagegen erstmals über eine Korrelation von klinischem Outcome und PD-L1-Expression berichtet. Die PD-L1-Expression allein reichte jedoch nicht aus, um Patienten auszuwählen, die möglicherweise von einer Immuntherapie profitieren. In zahlreichen Studien wurde versucht, präzisere, aus Tumorgewebe oder dem peripheren Blut stammende Marker zu finden. In der vorliegenden Übersichtsarbeit sollen sämtliche Charakteristika des Immunogramms, die als prädiktive Biomarker für das Ansprechen auf Immuncheckpoint-Inhibitoren herangezogen werden können, untersucht werden. Ferner beschreiben wir die wichtigste genetische Veränderung, die als Prädiktor für die Wirksamkeit der Immuntherapie dienen könnte. @ 2020 Die Autoren. Lizenznehmer MDPI, Basel, Schweiz Published by S. Karger GmbH, Freiburg

\section{Einführung}

Durch die Einführung von Immuncheckpoint-Inhibitoren (ICIs) konnte das Outcome von Patienten mit nicht kleinzelligem Lungenkarzinom (non-small cell lung cancer, NSCLC) in den vergangenen Jahren deutlich verbessert werden. Nach wie vor besteht jedoch ein ungedeckter Bedarf in Hinblick auf die Identifizierung von Patienten, die am stärksten von ICIs profitieren würden. In den ersten Studien mit Nivolumab erfolgten keine auf prädiktiven Biomarkern basierenden Outcome-Analysen. Im Jahr 2016 wurden in der OAK-Studie zu Atezolizumab und der KEYNOTE010-Studie zu Pembrolizumab erstmals Daten zur Korrelation

\section{Karger"} GOPEN ACCESS (c) 2020 Die Autoren. Lizenznehmer MDPI, Basel, Schweiz Published by S. Karger GmbH, Freiburg

This article is licensed under the Creative Commons Attribution 4.0 International License (CC BY) (http://www.karger.com/Services/OpenAccessLicense). Usage, derivative works and distribution are permitted provided that proper credit is given to the author and the original publisher.
Giovanni Rossi

Lung Cancer Unit, Medical Oncology

IRCCS Ospedale Policlinico San Martino

13132 Genua, Italien

giovanni.rossi.1689@gmail.com 
von klinischem Outcome (Ansprechen und Überleben) und PDL1 (programmed death-ligand 1)-Expression in Tumorgewebeproben vorgestellt [1-4].

Seither wurden zahlreiche retrospektive Studien und Subgruppenanalysen durchgeführt, die die Bedeutung der PD-L1-Expression als prädiktiver Biomarker für die Wirksamkeit der Immuncheckpoint-Inhibitoren bestätigten. Allerdings liegen Hinweise vor, nach denen manche Patienten auch bei niedriger oder fehlender PD-L1-Expression auf die Therapie ansprechen können. Zudem wurde die Hypothese, der zufolge die PD-L1-Expression allein für eine effiziente Patientenselektion nicht ausreicht, durch die Heterogenität und die Mutabilität der PD-L1-Expression im Zeitverlauf gestützt. All diese Ergebnisse förderten die Erforschung neuer Biomarker. Das Verständnis des komplexen Zusammenspiels von Immunsystem und molekularer Tumorbiologie könnte zur Definition eines umfassenden Schemas führen, das helfen kann, die Therapie in bestimmten Situationen voranzubringen. Ziel der vorliegenden Übersichtsarbeit ist es, den State-of-the-Art der Biomarker-Forschung zu beschreiben, um eine Orientierungshilfe für die ICI-Therapie zu bieten. Darüber hinaus soll der aktuelle Wissensstand über zugelassene und experimentelle Substanzen, die aus Gewebe stammen oder im Blut zirkulieren, vertieft werden.

\section{Establierte Biomarker}

\section{Gewebe-PD-L1}

Das programmed death protein 1 (Programmierter Zelltod-Protein 1) PD-1 (oder CD279) ist ein Transmembranglykoprotein, das in verschiedenen Subtypen von B- und T-Lymphozyten, natürlichen Killerzellen, Monozyten, Langerhans-Zellen und antigen-präsentierenden Zellen (APCs) [5] exprimiert wird und für die Verhinderung von Autoimmunität von zentraler Bedeutung ist. Die Expression von PD-1 wird durch proinflammatorische Zytokine (INF, IL4, TNF, VEGF) induziert. Es wirkt, indem es an programmed death-ligand 1 (Programmierter Zelltod-Ligand 1, PD-L1, oder B7-H1 oder CD274) und PD-L2 (B7-DC oder CD273) bindet, die auf APCs, Endothelzellen, dendritischen Zellen und Makrophagen exprimiert werden [6, 7]. Diese Achse ist einer der wichtigsten Mechanismen der peripheren Immuntoleranz und der Regulation der T-Zell-Aktivierung und umfasst auch andere Mitglieder der B7-Familie wie B7-1 (CD80) und B7-2 (CD86) sowie ihre jeweiligen Liganden CD28 und CTLA-4 $[5,6]$. PD-L1 scheint bei NSCLC ein negativer prognostischer Faktor zu sein, doch ist seine Bedeutung derzeit noch strittig [8].

Von den 4 unterschiedlichen immunhistochemischen (IHC) Antikörpern SP124, 22C3, 28-8 und SP263, die für die Analyse von PD-L1 bei Lungenkrebs zugelassen wurden, weisen die letzten 3 die höchste Konkordanz auf [9-11].

Die Bestimmung der PD-L1-Expression in Tumorproben ist gegenwärtig der einzige zugelassene Biomarker, der die ICI-Therapie in der klinischen Praxis voranbringt, da er eine Selektion der Patienten ermöglicht und prädiktiv für das Ansprechen auf PD-1/ PDL1-Inhibitoren ist [12]. Eine kürzlich veröffentlichte Studie be- wertete die Bedeutung von PD-L1 als prädiktiver Biomarker über alle Studien hinweg, die zur Zulassung von ICIs durch die USamerikanische Arzneimittelaufsichtsbehörde (Food and Drug Administration, FDA) geführt haben. Dabei wurden alle zwischen 2011 und April 2019 durchgeführten positiven Studien (45 Medikamente bei 15 verschiedenen Krebsarten) berücksichtigt: PD-L1 erwies sich in weniger als $30 \%$ der Fälle als prädiktiv und in mehr als 50\% als nicht prädiktiv. Darüber hinaus wurden in den verschiedenen Studien unterschiedliche PD-L1-Schwellenwerte verwendet (selbst wenn die Studien den gleichen Tumortyp betrafen) [13]. Diese Ergebnisse relativieren die prädiktive Bedeutung von PD-L1 und unterstreichen, dass sein Nutzen als Prädiktor für das Ansprechen auf die Immuntherapie bei Krebs begrenzt ist. So zeigte sich beispielsweise, dass die Expression von PD-L1 mit einem klinischen Ansprechen auf Nivolumab als SecondLine-Therapie (Studie CheckMate 057) bei nicht plattenepithelialem NSCLC sowie auf Pembrolizumab (KEYNOTE-010) und Atezolizumab (OAK) bei plattenepithelialem und nicht plattenepithelialem NSCLC assoziiert war, jedoch weder prognostische noch prädiktive Bedeutung für den Benefit durch Nivolumab bei plattenepithelialem NSCLC (CheckMate 017) besaß [1-4, 10, 14]. Eine im Jahr 2017 aktualisierte Netzwerk-Metaanalyse untersuchte die prädiktive Bedeutung der PD-L1-Expression bei 2015 NSCLC-Patienten, die Anti-PD-1/PD-L1-Antikörper (als Monooder Kombinationstherapie) erhalten hatten, indem die verfügbaren Daten aus allen veröffentlichten Studien gepoolt wurden [15, 16]. In allen 14 ausgewählten Studien erfolgte die PD-L1-Bewertung mit unterschiedlichen IHC-Tests. Entsprechend dem positiven oder negativen PD-L1-Status (der in jeder Studie einzeln definiert wurde) wurden die Gesamtansprechrate (overall response rate, ORR) und die Hazard Ratio (HR) für das progressionsfreie Überleben (progression-free survival, PFS) sowie das Gesamtüberleben (overall survival, OS) berichtet. Bei 931 PD-L1-positiven und 1084 PD-L1-negativen Patienten betrug die ORR 27,6\% bzw. 12,1\%. Die ORR fiel bei den PD-L1-positiven Patienten unabhängig von der Tumorhistologie und der ICI-Therapielinie signifikant höher aus (relatives Verhältnis (relative ratio, RR) 2,19, 95\%-KI: 1,63-2,94; $\mathrm{p}<0,01$ ). Die ORR nahm proportional zur PD-L1-Expression zu. Bei Begrenzung der Analyse auf die Erstlinientherapie betrug die ORR für die beiden Gruppen $40 \%$ gegenüber 20\% (RR: 1,96, 95\%-KI: 0,99-3,90; p = 0,05). Das PFS wurde in 6 Studien $(n=897)$ berichtet und es bestand ein signifikanter Unterschied zwischen PD-L1-positiven und -negativen Patienten zugunsten der ersten Gruppe (HR: 0,69, 95\%-KI: 0,57-0,85; p < $0,01)$. In 8 Studien $(\mathrm{n}=1522)$ wurde das OS untersucht und eine längere Überlebensdauer von Patienten mit PD-L1-Expression auf den Tumorzellen beobachtet (HR: 0,77, 95\% KI: 0,67-0,89; $\mathrm{p}<0,01)[16]$.

Im Erstlinien-Setting bei NSCLC wird die ICI-Monotherapie streng durch einen PD-L1-Tumorproportionsscore (TPS) von $\geq 50 \%$ bestimmt, da nur in dieser Situation ein OS-Vorteil gegenüber der platinbasierten Chemotherapie nachweisbar war. Tatsächlich war die KEYNOTE-024-Studie so geplant, dass nur Patienten eingeschlossen wurden, deren Tumor eine hohe PD-L1- 
Expression zeigte, wohingegen in KEYNOTE-042 Patienten mit einem PD-L1-TPS $\geq 1 \%$ eingeschlossen wurden. In beiden Studien wurden Pembrolizumab mit einer platinbasierten Chemotherapie verglichen und die Endpunkte erreicht. Eine explorative Analyse von KEYNOTE-042 sprach allerdings dafür, dass der im Pembrolizumab-Arm beobachtete Vorteil stark durch den Anteil der Patienten mit einem TPS $>50 \%$ beeinflusst war, die einen erheblichen Teil der PD-L1-positiven Patienten ausmachten [17-19]. Dagegen wurde der durch die Zugabe von Anti-PD-1/PD-L1Wirkstoffen zu den Standard-Chemotherapieschemata erzielte OS-Benefit in den Studien, die Kombinationstherapien von ICIs und Chemotherapie untersuchten, sofern nachweisbar, unabhängig von der PD-L1-Konzentration beobachtet (KEYNOTE-189, KEYNOTE-407, IMPOWER 150) [19-22]. In Tabelle 1 sind die Hauptmerkmale der wichtigsten Studien, in denen die Bedeutung der PD-L1-Expression bei der Selektion der Patienten für eine ICIBehandlung untersucht wurde, zusammengefasst.

Aufgrund verschiedener Merkmale gilt PD-L1 derzeit als ein zwar mangelhafter, aber notwendiger Biomarker: Krebstherapien können die PD-L1-Expression verändern [11]. Dies kann nach Exposition gegenüber lokoregionalen oder systemischen Behandlungen wie Strahlentherapie (radiation therapy, RT) oder Chemotherapie auftreten. So wurde beispielsweise bei 76 NSCLC-Patienten, die während ihrer antineoplastischen Behandlung untersucht wurden, die PD-L1-Expression auf Tumorzellen mittels IHC getestet und vor und nach der Behandlung verglichen: In 29 Fällen fand sich eine deutliche Änderung der PD-L1-Expression (d.h. von negativ $\mathrm{zu} \geq 1 \%$ oder $\geq 50 \%$ und umgekehrt) [23].

PD-L1 zeigt eine intratumorale Heterogenität, weshalb das Risiko besteht, dass die diagnostische Biopsie nicht repräsentativ für die Neoplasie als Ganzes ist $[11,24]$. Insbesondere bestand eine hohe Diskordanz bei der PD-L1-Expression zwischen chirurgischen Proben von reseziertem NSCLC und den entsprechenden Gewebeproben, die durch diagnostische Biopsie gewonnen wurden [25]. Eine Heterogenität ist, wenn auch seltener, auch bei primitiven Tumoren und Metastasen zu beobachten [26].

Es war nicht sicher, ob sich Archivproben für PD-L1-Testungen eignen, da die zur Fixierung und Konservierung eingesetzten Verfahren die Qualität des Gewebes verändern können. Eine vorab festgelegte explorative Analyse der KEYNOTE-010-Studie, in der Pembrolizumab mit Docetaxel bei vorbehandelten Patienten mit PD-L1-positivem fortgeschrittenen NSCLC verglichen wurde, berichtete jedoch Ergebnisse auf Basis der PD-L1-Expression in Archivproben $(\mathrm{n}=455)$ im Vergleich zu neu gewonnenen Tumorproben $(n=578)$. Bei Patienten mit einem TPS $\geq 1 \%$ kam es unter der Anti-PD-1-Verbindung unabhängig von den Merkmalen der verwendeten Probe zu einer Verbesserung der HR für das Gesamtüberleben: Die HR lag bei 0,74 (95\%-KI: 0,59-0,93) und 0,59 (95\%-KI: 0,48-0,73) für archivierte bzw. neu gewonnene Proben. Ebenso fiel die HR für das progressionsfreie Überleben bei den archivierten und neu gewonnenen Proben ähnlich aus: 0,82 (95\%-KI: 0,66-1,02) bzw. 0,83 (95\%-KI: 0,68-1,02) [27].

Zytologische diagnostische Proben zur Beurteilung des PD-L1TPS wurden in klinischen Studien in der Regel ausgeschlossen.
Allerdings ist die Gewinnung von histologischem Material in der klinischen Praxis oftmals schwierig, wohingegen die transbronchiale Nadelaspiration ein häufig eingesetztes diagnostisches Verfahren ist [11]. Alternativ kann die Beurteilung der PD-L1Expression an Zellblöcken erfolgen, wenn histologische Proben nicht zur Verfügung stehen [28]. Insgesamt scheint es sich bei PDL1 um einen robusten Biomarker zu handeln, der etliche Einschränkungen aufweist. Wie wir im Folgenden erläutern werden, könnten andere, neu aufkommende Biomarker seine Leistungsfähigkeit wesentlich verbessern.

\section{Gewebe-TMB}

Berichten zufolge ist das vermehrte Neuauftreten somatischer Mutationen im Verlauf der Tumorgenese mit der Bildung von Neoantigenen und der Entwicklung von Immunogenität assoziiert. Daher wurde postuliert, dass Tumoren, die eine höhere Zahl somatischer Mutationen aufweisen, unter Umständen empfindlicher gegenüber einer Immuncheckpoint-Blockade (ICB) sind. Die Tumormutationslast (tumor mutational burden, TMB) ist definiert als Gesamtzahl der nicht synonymen Mutationen je codierender Region eines Tumorgenoms und wird als Mutationen pro DNA-Megabase (Mb) berechnet [29-31].

Die ersten klinischen Erfahrungen mit der TMB-Berechnung wurden mit der Sequenzierung des gesamten Exoms (whole exome sequencing, WES) gemacht. Da diese Methode jedoch teuer und zeitaufwändig ist, wurden in der Folge neuartige gezielte Panels für die TMB-Bestimmung untersucht [32]. In Bezug auf die Verwendung der gewebebasierten TMB bei NSCLC wurde eine negative prognostische Bedeutung in einer Patientenpopulation beobachtet, die eine Operation, jedoch keine Chemotherapie oder Immuntherapie erhalten hatte [33]. Die Bedeutung der GewebeTMB als potenzieller Prädiktor für den Benefit durch eine Immuntherapie wurde initial in Patientenkohorten untersucht, die mit Immuncheckpoint-Inhibitoren als Monotherapie behandelt wurden (Tab. 2). Die Rolle der mittels WES bestimmten GewebeTMB wurde in 2 getrennten Kohorten von NSCLC-Patienten, die Pembrolizumab erhielten, untersucht (eine Discovery-Kohorte, $\mathrm{n}$ $=16$, und eine Validierungskohorte, $\mathrm{n}=18$ ). In dieser Studie kam es bei Patienten mit einer TMB > 209 Mutationen/Probe (Median der Discovery-Kohorte) in beiden Kohorten zu einer signifikanten Verbesserung des anhaltenden klinischen Benefits (partielles Ansprechen oder stabile Erkrankung für mehr als 6 Monate) und des PFS. Zudem war bei 73\% der Patienten mit hoher TMB gegenüber 13\% der Patienten mit niedriger TMB ein anhaltender klinischer Benefit zu beobachten $(p=0,04)$ [34]. Rizvi et al. zeigten in einer anderen Veröffentlichung, dass eine hohe TMB, die durch gezieltes NGS (MSK-IMPACT) beurteilt wurde, in einer Population von 240 NSCLC-Patienten, die Anti-PD-1- oder Anti-PD-L1Wirkstoffe erhielten, mit einem anhaltenden klinischen Benefit verbunden und unabhängig von der PD-L1-Expression war [35]. Die CheckMate-026-Studie, in der Nivolumab als Monotherapie mit einer platinbasierten Chemotherapie in der Erstlinientherapie bei fortgeschrittenem NSCLC verglichen wurde, beinhaltete als explorative Analyse eine Bewertung der WES-basierten Gewe-
302

Kompass Pneumol 2020;8:300-317 DOI: $10.1159 / 000511444$ 



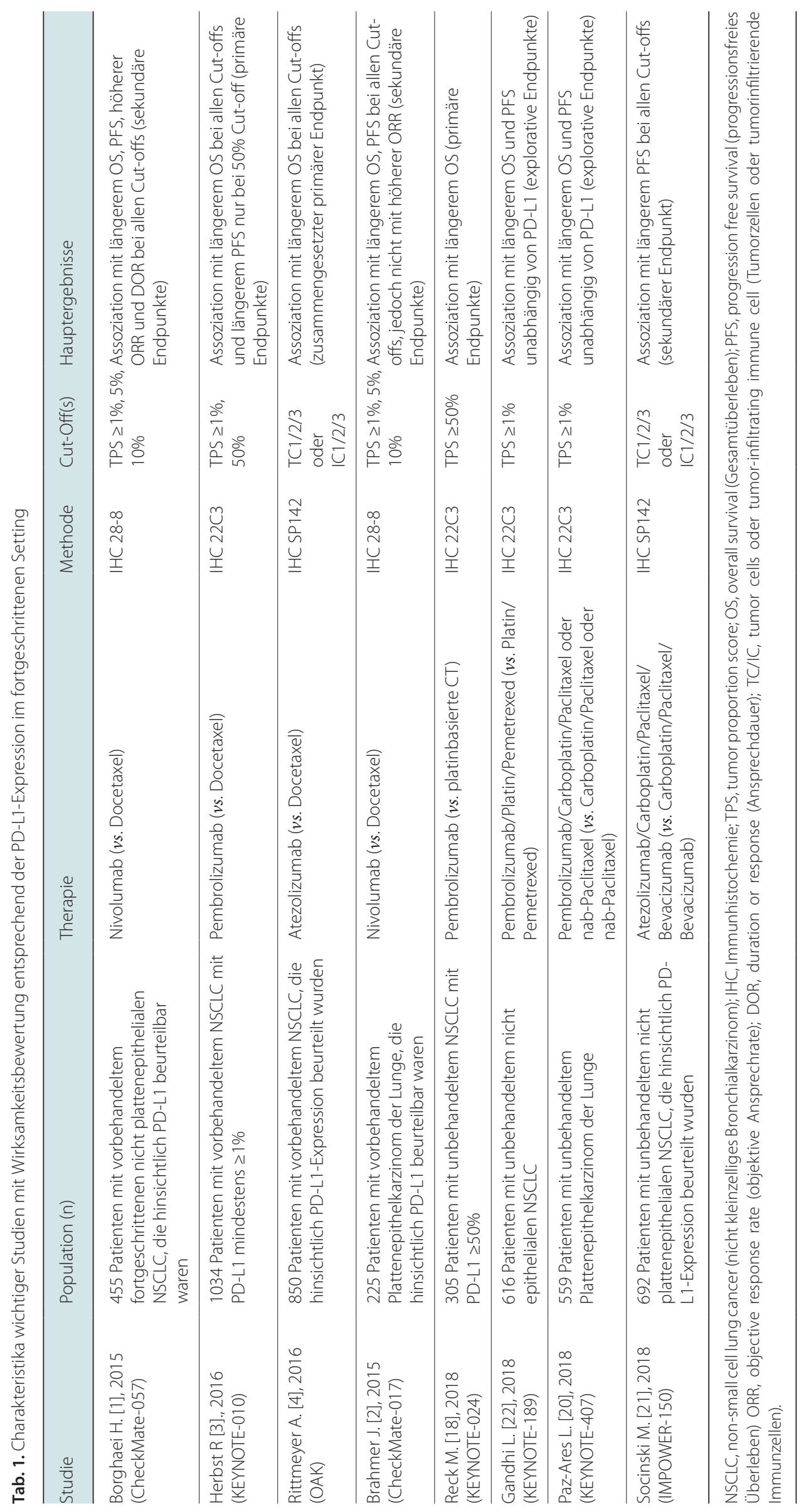




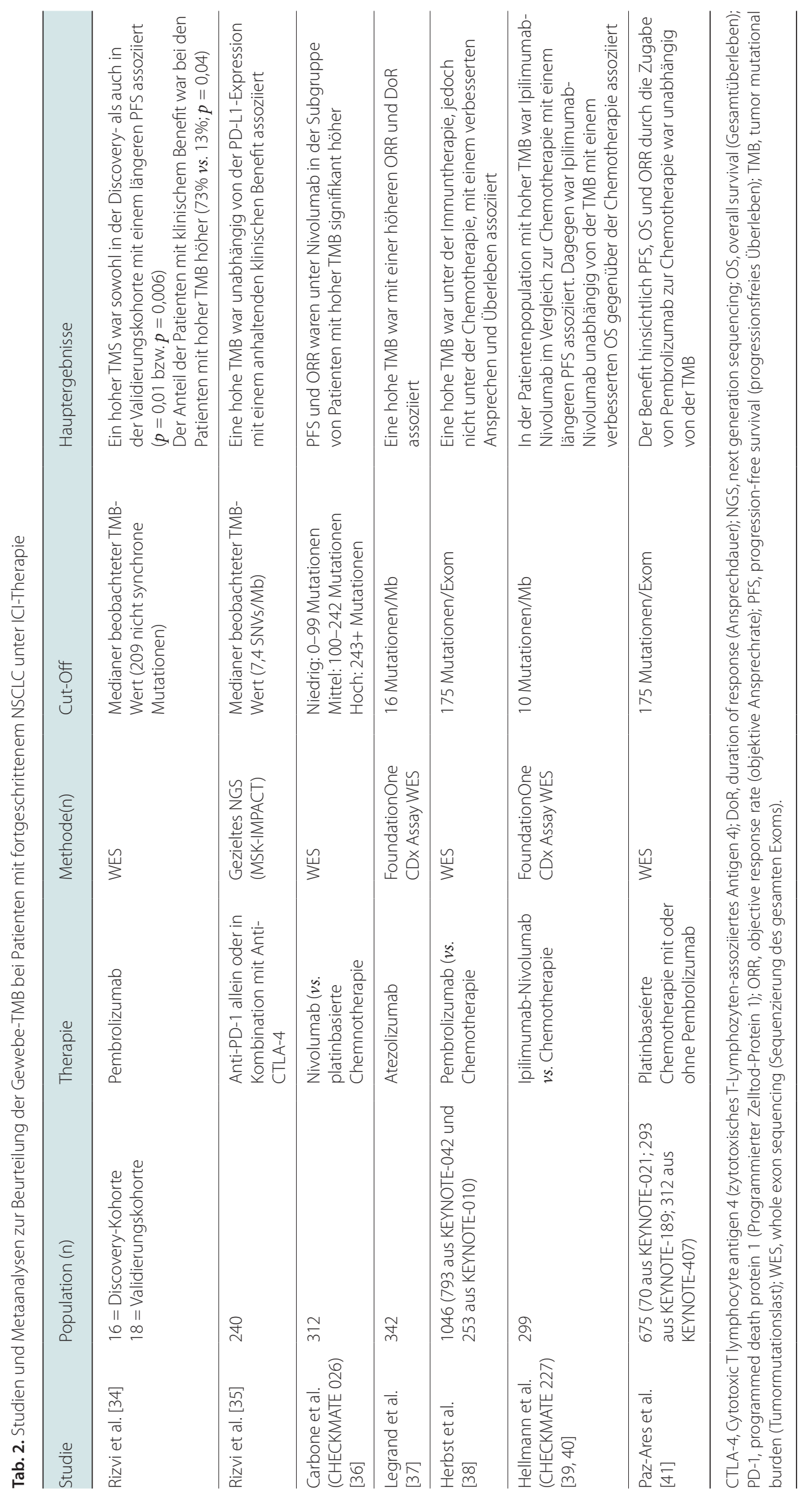


be-TMB, die als niedrig (0-100 Mutationen/Probe), mittel (100242 Mutationen/Probe) und hoch (243 Mutationen/Probe) definiert war. Zwar wurde der primäre Endpunkt (verbessertes PFS unter Nivolumab bei Patienten mit PD-L1 $\geq 5 \%$ ) der Studie nicht erreicht, doch fielen das PFS und die ORR unter Nivolumab in der Subgruppe der Patienten mit hoher TMB signifikant höher aus. In Hinblick auf das OS war kein Unterschied zu beobachten, wobei allerdings zu berücksichtigen ist, dass Patienten mit hoher TMB, die im Chemotherapie-Arm behandelt wurden, die Möglichkeit hatten, bei einer Krankheitsprogression in den Nivolumab-Arm zu wechseln [36]. Ebenso sprachen explorative Analysen von gepoolten Daten aus Studien mit Atezolizumab bei soliden Tumoren einschließlich NSCLC für eine mögliche positive prädiktive Bedeutung einer hohen Gewebe-TMB, die in diesem Fall durch die 75. Perzentile (hoch) und die 50. Perzentile (mittel) der jeweiligen studienspezifischen TMB definiert war [37]. Kürzlich analysierten Herbst et al. die gepoolten Daten aus der KEYNOTE-010- und KEYNOTE-042-Studie, in der Pembrolizumab mit Docetaxel (Second-Line-Therapie) bzw. mit einer platinbasierten Chemotherapie (First-Line-Therapie) bei PD-L1-positiven NSCLC-Patienten verglichen wurde. Dabei identifizierten sie die Gewebe-TMB, die gemäß einem vorab festgelegten explorativen Cut-off-Wert von 175 Mutationen/Exom definiert war und mittels WES bestimmt wurde, als potenziellen Prädiktor für das Outcome von Patienten, die Pembrolizumab als Monotherapie erhielten. Tatsächlich war eine hohe TMB mit einem verbesserten Ansprechen und Überleben unter der Immuntherapie verbunden, wohingegen keine Assoziation mit dem Ansprechen auf die Chemotherapie bestand [38].

Die Rolle des Gewebe-TMB bei Kombinationsschemata wurde in der Studie CheckMate 227 untersucht; genauer gesagt wurde die Studie ergänzt, so dass sie als zusammengesetzten primären Endpunkt den PFS-Vergleich zwischen Ipilimumab-Nivolumab und der First-Line-Chemotherapie bei Patienten mit hoher GewebeTMB (10 Mutationen/Mb, gemäß früheren Studien [31]) beinhaltete. Dabei fiel insbesondere das PFS unter Ipilimumab-Nivolumab signifikant länger aus als unter Chemotherapie. Nachdem jedoch die Daten für den anderen zusammengesetzten primären Endpunkt (OS bei Patienten mit PD-L1 > 1\%) vorlagen, zeigte sich, dass die besseren Ergebnisse von Ipilimumab-Nivolumab hinsichtlich des Gesamtüberlebens unabhängig von der TMB waren, wodurch die tatsächliche Rolle dieses Biomarkers in Frage gestellt wurde $[39,40]$. Und schließlich wurde die Gewebe-TMB in einer gepoolten Analyse der Studien KEYNOTE-021, KEYNOTE-189 und KEYNOTE-407 untersucht, die alle darauf ausgerichtet waren, den Benefit durch die Zugabe von Pembrolizumab zur platinbasierten Chemotherapie zu untersuchen (wobei in den Studien allerdings unterschiedliche Histologien untersucht wurden). Ähnlich wie in der Analyse von Herbst et al. [38] wurde dabei ein vorab festgelegter Cut-off-Wert von 175 Mutationen/Exom verwendet. In dieser Analyse fand sich kein signifikanter Zusammenhang zwischen der mittels WES beurteilten Gewebe-TMB und dem Benefit durch eine Zugabe von Pembrolizumab zur platinbasierten Chemotherapie hinsichtlich PFS, OS oder ORR [41].
Die Einführung dieses Tests in die klinische Routine ist schwierig, da eine Harmonisierung der TMB-Ansätze unabdingbar ist, um vergleichbare Ergebnisse verschiedener Studien zu gewährleisten. Anagnostou et al. beschrieben kürzlich einen Korrekturfaktor für die TMB, der an einer großen Kohorte von Tumorproben aus dem Genomkrebsatlas ermittelt und anschließend an einer zweiten Kohorte von Patienten, die ICIs erhielten, validiert wurde. Dieser Korrekturfaktor, der auf unterschiedlichen Tumor-Reinheitsgraden basiert, scheint den prädiktiven Wert der TMB hinsichtlich der Outcome-Prognose für Patienten, die mit ICIs behandelt werden, deutlich zu steigern. Dies lässt vermuten, dass die TMB in Proben von geringer Tumorreinheit möglicherweise stark unterschätzt wird, was eine fehlerhafte Einstufung von Patienten mit diesen Tumoren zur Folge haben kann.

Insgesamt lässt sich sagen, dass sich die TMB trotz einer ermutigenden Grundannahme und vielversprechender Daten aus Untersuchungen zu PD-1-Inhibitoren als Monotherapie nicht als wirksamer Prädiktor für den Benefit durch eine Immuntherapie, insbesondere in Hinblick auf das Gesamtüberleben und Kombinationsschemata, erwiesen hat. Bis jetzt ist die Gewebe-TMB noch nicht bereit für den Einsatz in der klinischen Praxis und ihre Verwendung außerhalb klinischer Studien, die auf eine Optimierung des Einsatzes dieses Biomarkers abzielen, sollte nicht unterstützt werden.

\section{Blutproben-TMB und PD-L1}

Die Liquid Biopsy (LB, Flüssigbiopsie) ist ein neues leistungsfähiges Instrument und wird bereits in der klinischen Praxis bei fortgeschrittenem NSCLC zur Tumorgenotypisierung mittels Analyse zellfreier DNA (cfDNA) eingesetzt sowie zur Beurteilung der Mechanismen der erworbenen Resistenz gegen TyrosinkinaseInhibitoren bei Patienten, die nach molekularen Kriterien ausgewählt wurden [42]. Gegenüber den herkömmlichen Gewebetests besitzt die Liquid Biopsy mehrere potenzielle Vorteile, da sie unter Umständen eine minimal-invasive Überwachung des Ansprechens auf Medikamente sowie eine bessere Definition unklarer klinischer/radiologischer Szenarien ermöglicht und möglicherweise die Tumorheterogenität und die dynamischen Veränderungen der Tumorbiologie unter dem selektiven Druck von antitumoralen Therapien genauer wiedergibt $[43,44]$.

Um einige der Einschränkungen der PD-L1-IHC-Testung zu überwinden, wie etwa, dass bei bis zu 30\% der NSCLC-Patienten kein Gewebe für molekulare Tests zur Verfügung steht [45] sowie die räumliche/zeitliche Heterogenität der IHC-Expression [46], untersuchten einige Studien den löslichen PD-L1 (sPD-L1) oder die PD-L1-Expression in zirkulierenden Tumorzellen (circulating tumor cells, CTCs) als alternative Quelle für die PD-L1-Beurteilung und als dynamischen Biomarker bei Patienten, die herkömmliche Behandlungen [47-49] und/oder ICIs erhielten [5054]. Hohe, mittels ELISA (enzyme linked immunosorbent assay) bestimmte Ausgangskonzentrationen von sPD-L1 sind ein ungünstiger prognostischer Faktor bei Lungenkrebs und scheinen mit einem geringeren Ansprechen auf eine PD-1-Blockade assoziiert zu sein [55]. Änderungen der sPD-L1-Konzentration unter
306

Kompass Pneumol 2020;8:300-317 DOI: $10.1159 / 000511444$ 
der Behandlung mit ICIs waren jedoch mit widersprüchlichen Ergebnissen assoziiert [54]. Interessanterweise sprechen einige $\mathrm{Da}-$ ten dafür, dass eine First-Line-Chemotherapie (z.B. mit Platin und Pemetrexed) zu einem signifikanten Anstieg der medianen sPD-L1-Konzentration gegenüber dem Ausgangswert führen kann, wohingegen gezielte Therapien die sPD-L1-Konzentration scheinbar nicht veränderten [47].

Wegen der geringen Zahl der in diese Studien eingeschlossenen Patienten und der unterschiedlichen verwendeten Assays ist es nicht möglich, endgültige Schlussfolgerungen zu ziehen.

Andere Studien, in denen der Schwerpunkt auf der Bewertung der PD-L1-Expression auf CTCs mittels Immunfluoreszenz lag, berichteten über einen unterschiedlichen Grad an Konkordanz mit der PD-L1-IHC-Expression im Gewebe [49, 52, 53, 56]. Interessanterweise scheint ein Anstieg der PD-L1-positiven CTCs unter der Behandlung mit ICIs mit einer Krankheitsprogression assoziiert zu sein $[52,53]$ und dies könnte ein potenzieller minimalinvasiver Biomarker für Resistenz sein, der die herkömmliche radiologische Beurteilung in Fällen mit unsicherer Krankheitsprogression (Pseudoprogression oder gemischtes Ansprechen) unterstützen kann. Ferner scheint die Zahl der CTCs ein Prädiktor für das Outcome von NSCLC-Patienten, die mit ICIs behandelt werden, zu sein, da ein höherer CTC-Ausgangwert mit einem kürzerer PFS $[53,57]$ und OS $[53,57,58]$ assoziiert war.

Neben den CTCs untersuchten mehrere neuere Studien die potenzielle Bedeutung der cfDNA-Analyse als prädiktiver Biomarker bei NSCLC-Patienten, die eine Immuncheckpoint-BlockadeTherapie erhielten. In diesen Studien lag der Schwerpunkt entweder auf der Untersuchung der Dynamik zirkulierender Tumor-DNA (ctDNA) oder auf der Identifizierung von neu aufkommenden Biomarkern im Plasma, die zuvor im Gewebe untersucht wurden, wie beispielsweise die TMB. Ein signifikanter Rückgang der zirkulierenden Tumor-DNA (ctDNA) unter der Behandlung mit ICIs war in mehreren Studien, in denen unterschiedliche Methoden und Definitionen für ein molekulares Ansprechen verwendet wurden, mit einem radiologischen Ansprechen und verbesserten Outcomes von Patienten mit fortgeschrittenem NSCLC assoziiert (Tab. 3). Darüber hinaus ist die ctDNA-Dynamik Berichten zufolge im Vergleich zu den herkömmlichen radiologischen Methoden in der Lage, das Ansprechen des Tumors vorherzusagen, was eine genauere Unterscheidung von komplexen oder unklaren klinischen Szenarien wie Pseudoprogression und Krankheitsstabilisierung ermöglichen könnte [59] und möglicherweise ein hilfreiches Instrument in klinischen Studien darstellt, in denen ein elektives Absetzen der Behandlung bei Patienten ohne Krankheitsprogression nach 1- bis 2-jähriger ICB-Therapie bewertet wird.

Überdies könnte die ctDNA-Analyse eine alternative Methode zur TMB-Beurteilung darstellen. Die wichtigste Einschränkung für die klinische Durchführung von Gewebe-TMB-Tests bei fortgeschrittenem NSCLC ist die fehlende Verfügbarkeit von ausreichend Archiv-/Frischmaterial bei einem Großteil der Patienten; in neueren klinischen Studien betrug der Anteil der auswertbaren Proben für ein WES oder gezieltes NGS lediglich 34-59\% [60]. Die prädiktive Bedeutung der TMB auf cfDNA (sogenannte BlutTMB, bTMB) bei NSCLC-Patienten unter ICI-Therapie wurde kürzlich in mehreren Studien untersucht. Gandara et al. berichteten als Erste über die Entwicklung, Testung und Validierung des 394-gene FoundationMedicine (FMI) bTMB Assays. Die Wissenschaftler analysierten retrospektiv Plasmaproben aus der randomisierten Phase-II-Studie POPLAR (Trainingsset) und der Phase-III-Studie OAK (Validierungsset) und identifizierten einen bTMB-Wert von $\geq 16$ Mutationen pro Megabase (Mut/Mb) als klinisch relevanten und technisch robusten Cut-off-Wert zur Vorhersage des Benefits durch Atezolizumab bei Patienten mit NSCLC. Eine hohe bTMB war ein unabhängiger prädiktiver Biomarker für das PFS und nicht mit einer hohen PD-L1-IHC-Expression assoziiert, wie dies zuvor für Gewebe berichtet wurde [45]. Eine prospektive Bewertung dieses bTMB-Assays erfolgte in der unverblindeten Phase-II-Studie Blood First-Line Ready Screening Trial (B-F1RST), in der die Wirksamkeit und Sicherheit der FirstLine-Monotherapie mit Atezolizumab bei Patienten mit lokal fortgeschrittenem oder metastasiertem NSCLC vom EGFR/ALKWildtyp unabhängig von der PD-L1-Expression untersucht wurde. Die Biomarker-evaluable-Population (BEP) umfasste Patienten mit einer auswertbaren Ausgangsblutprobe mit einer maximalen somatischen Allelfrequenz (MSAF) $\geq 1 \%$ und einer bTMB $\geq 16$, die signifikant mit einer höheren ORR $(p=0,0002)$ und einer numerischen Verbesserung des PFS (4,6 vs. 3,7 Monate, $\mathrm{p}=0,12$ ) und OS (nicht auswertbar vs. 13,1 Monate, $\mathrm{p}=0,48$ ) assoziiert war [61]. Zurzeit erfolgt die prospektive Validierung von $\mathrm{bTMB} \geq 16$ in einer Kohorte der Phase-III-Studie Blood-First Assay Screening Trial (B-FAST, NCT03178552) und die Ergebnisse werden mit Spannung erwartet. Ein zweiter bTMB-Assay, der das $500-$ Gen Panel Guardant OMNI verwendet, wurde in einer explorativen Analyse der randomisierten Phase-III-Studie MYSTIC bewertet. Bei einer $\mathrm{bTMB} \geq 20 \mathrm{Mut} / \mathrm{Mb}$ bestand eine signifikante Assoziation mit einem OS- und PFS-Benefit unter Durvalumab \pm Tremelimumab gegenüber einer platinbasierten Chemotherapie, wobei der größte Benefit bei Patienten nachweisbar war, die eine duale Immuncheckpoint-Blockade erhielten (HR: 0,49 und 0,72 für das OS und HR: 0,53 und 0,77 für das PFS unter DurvalumabTremelimumab bzw. Durvalumab als Monotherapie)[62]. Hier bestand ebenfalls keine Korrelation zwischen der bTMB und der Höhe der PD-L1-Expression. Die prädiktive Bedeutung der mittels GuardantOMNI bestimmten bTMB bei Pembrolizumab als Monotherapie $(\mathrm{n}=31)$ oder in Kombination mit einer Chemotherapie $(\mathrm{n}=35)$ wurde prospektiv in einer kleinen monozentrischen Studie beurteilt. Eine bTMB $>16 \mathrm{Mut} / \mathrm{Mb}$ war mit verbesserten Outcomes nach einer Pembrolizumab-basierten First-Line-Therapie assoziiert, und die gleichzeitige Bewertung negativer Prädiktoren in der Liquid Biopsy (d.h. Mutationen in STK11/KEAP1/ PTEN und ERBB2) steigerte ihren prädiktiven Wert sowohl für das PFS (HR: 0,27 und 0,18 für bTMB allein und bTMB plus negative Prädiktoren) als auch für das OS (HR: 0,47 und 0,27 für bTMB allein und bTMB plus negative Prädiktoren) [63]. Diese Ergebnisse unterstreichen die potenzielle Bedeutung des plasmabasierten NGS, das über die Tumor-Genotypisierung von onko- 


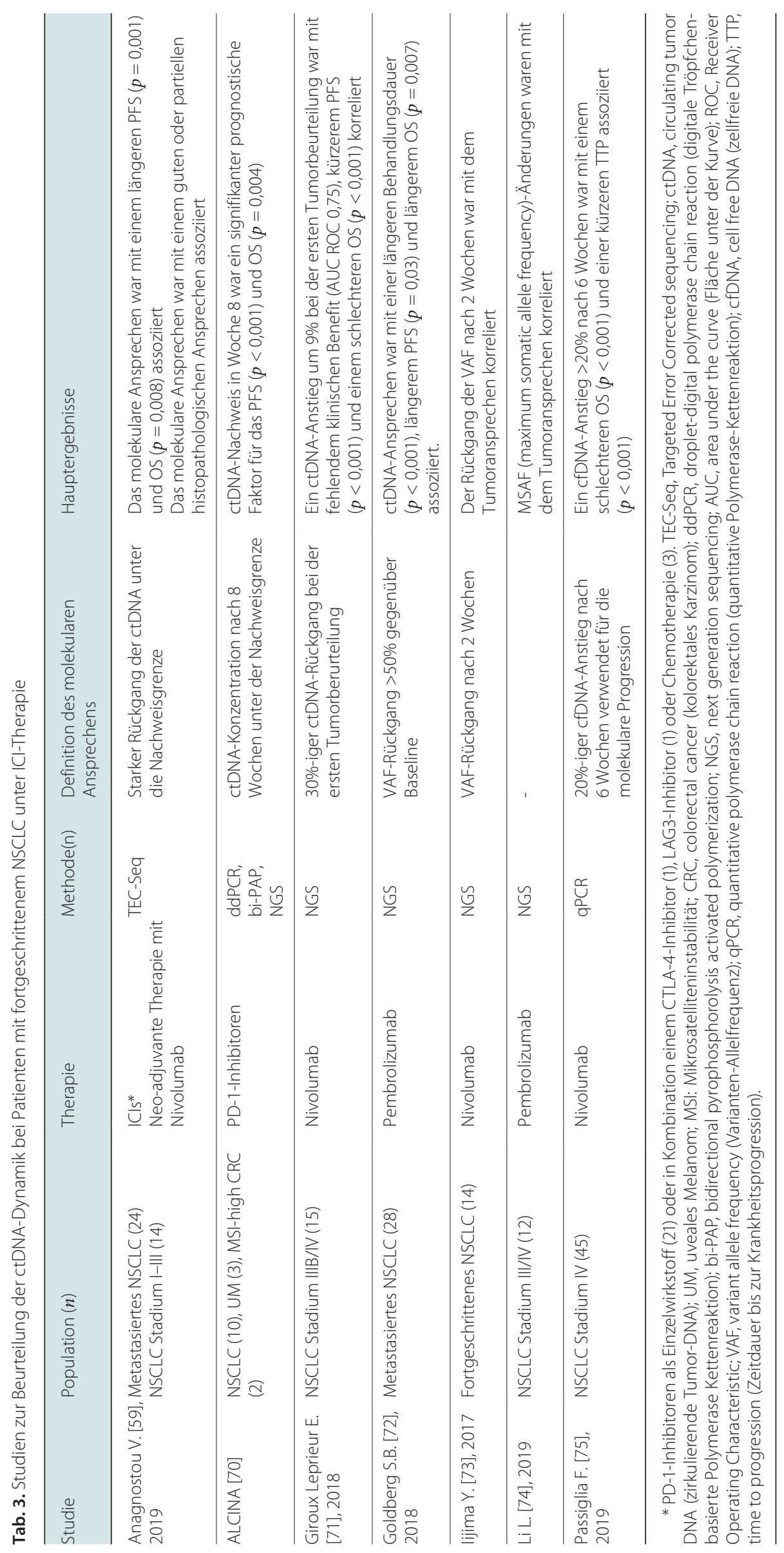



gen-abhängigen NSCLCs hinausgeht, und könnten hilfreiche Informationen für Patienten liefern, die Kandidaten für eine Behandlung mit ICIs sind, darunter auch die Identifizierung von Begleitmutationen, die mit schlechteren Outcomes unter diesen Wirkstoffen verbunden sind.

Die Konkordanz zwischen diesen beiden plasmabasierten NGSAssays für die bTMB-Bestimmung ist unklar. Allerdings zeigte eine kürzlich durchgeführte Studie zum metastasierten, kastrationsresistenten Prostatakarzinom, in der ein Vergleich von FoundationMedicine bTMB-Assay, GuardantOMNI und WES an Gewebe erfolgte, dass zwischen den beiden plasmabasierten TMBAssays eine hohe Korrelation besteht, und beide zudem mit einem gewebebasierten TMB-Assay bei Proben mit relativ hoher TMB korrelieren; bei Proben mit niedriger/mittlerer TMB fiel die Korrelation jedoch geringer aus, was wahrscheinlich auf biologische Unterschiede zurückzuführen ist [64].

Neben den beiden kommerziellen plasmabasierten NGS-Plattformen nahmen Wang et al. kürzlich eine Bewertung der Bedeutung eines neuartigen 150-Gen-NGS-Panels namens NCC-GP150 vor, das mit Hilfe der Datenbank The Cancer Genome Atlas (TGCA) entwickelt und virtuell validiert wurde. In einer Kohorte von 48 NSCLC-Patienten mit gematchten Blut- und Gewebeproben bestand eine signifikante Korrelation zwischen der Blut-TMB und der Gewebe-TMB gemäß WES. Diese wurde anschließend in einer unabhängigen NSCLC-Kohorte von 50 Patienten, die mit PD(L)-1-Inhibitoren behandelt wurden, validiert. Eine bTMB $\geq 6$ war mit einer signifikant höheren ORR (39,3\% vs. 9,1\%, p = 0,02) und einem längeren PFS (HR: 0,39; $p=0,01$ ) assoziiert [65]. Georgiadis et al. setzten darüber hinaus ein zielgerichtetes HybridCapture-NGS-System (Agilent SureSelect XT In-Solution-Hybrid-Capture-System) ein. Dem Custom-Panel zufolge, bei dem ein validierter Cut-off-Wert von 5 Mutationen verwendet wurde und das auf die vordefinierten interessierenden Regionen über 58 Gene hinweg abzielte, ist eine hohe bTMB vor der PD-1-Blockade bei soliden Tumoren prädiktiv für das PFS (HR: 0,23, p = 0,003). Ferner berichteten sie, dass eine hohe MSI (nachgewiesener Anteil von $\geq 20 \%$ der Loci) im Plasma vor der Behandlung mit einem verbesserten PFS (HR: 0,21, p = 0,001) assoziiert war. Dabei war das Ansprechen mit dem bTMB-Status assoziiert, da alle 5 MSIhigh-Patienten, die auf die PD-1-Blockade ansprachen, eine hohe bTMB aufwiesen, wohingegen 6 von 7 Patienten mit Krankheitsprogression und MSI-high-Status eine niedrige bTMB zeigten [66].

Insgesamt handelt es sich bei der bTMB um einen aussichtsreichen prädiktiven Biomarker für die ICI-Therapie bei fortgeschrittenem NSCLC, doch sind vor seiner klinischen Einführung weitere prospektive Studien erforderlich. Neben der bTMB-Bestimmung könnte die cfDNA-Analyse mithilfe plasmabasierter NGS-Panels zusätzliche nützliche Informationen liefern, wie etwa das gleichzeitige Vorliegen von somatischen Mutationen, deren Auftreten im Gewebe mit einer primären Resistenz gegen PD(L)-1-basierte Therapien (z.B. STK11, KEAP1) [67, 68] oder mit verbesserten Outcomes unter PD-1- plus CTLA-4-Blockade (z.B. ARIAD1) in Verbindung gebracht wurde [68], und sie könnte ei- nen erheblichen Teil von Patienten mit onkogen-abhängigem NSCLC und unvollständigem molekularen Profiling [69], die weniger von einer ICB profitieren, retten.

\section{Tumorinfiltrierende Lymphozyten (TILs bei Lungenkrebs)}

Die Bestimmung des tumoralen Immunmikromilieus (tumor immune microenvironment, TME) ist zu einem interessanten biologischen und klinischen Biomarker geworden, da zahlreiche Daten die prognostische und potenziell prädiktive Bedeutung von tumorinfiltrierenden Lymphozyten (TILs) bei vielen verschiedenen Tumorarten stützen [76].

Insgesamt wurde das Vorliegen und die Anzahl der TILs bei vielen verschiedenen Krebsarten mit einer verbesserten Prognose in Verbindung gebracht $[77,78,79,80]$. In der Tat sind die Lokalisation, Dichte und funktionelle Ausrichtung des TME von zentraler Bedeutung für die Steuerung der Entwicklung oder Rückbildung des Tumors. Das TME besteht aus Lymphozyten (T- und B-Zellen), die für die adaptive Immunität verantwortlich sind, und myeloischen Zellen, die sowohl an der angeborenen als auch an der adaptiven Immunität beteiligt sind. Alle diese Elemente kommunizieren über aus dem Tumor freigesetzte Zytokine und Neoantigene miteinander, mit dem Stroma sowie mit den Tumorzellen [81].

Die verschiedenen TILs haben im TME unterschiedliche Funktionen und wirken sich klinisch unterschiedlich aus. Zytotoxische CD8-positive-Zellen sind in der Lage, Krebszellen direkt abzutöten, wohingegen CD4-positive Zellen eine heterogene Klasse von Zytokin-freisetzenden Lymphozyten sind (Th1, Th2, Th17 und Treg CD4+), die an der Aktivierung und Hemmung von CD8positiven Zellen beteiligt sind (IFN- $\gamma$, IL2, die von Th1-Zellen sezerniert werden, und IL-4, IL-5, IL-9, IL-10, IL-13, IL-25, die von Th2-Zellen sezerniert werden) [78, 79]. CD45RO-positive T-Zellen bilden eine weitere TIL-Subklasse, die als Gedächtnis-T-Lymphozyten gelten. Regulatorische T-Zellen (Tregs) besitzen eine immuninhibitorische Funktion und sind in der Lage, das immunologische Gleichgewicht aufrechtzuerhalten; diese Zellen werden durch den Transkriptionsfaktor FOXP3 in ihrer Entwicklung und Funktion reguliert.

Die optimale Methode zur Bewertung der TIL-Untergruppen ist die Immunhistochemie. Gleichwohl haben mehrere Studien die TIL-Gesamtkonzentration mithilfe der Standardfärbung durch Hämatoxylin-Eosin (HE) untersucht und einen starken prognostischen und prädiktiven Einfluss festgestellt [81]. In mehreren NSCLC-Studien erfolgte eine TIL-Bewertung anhand von HERoutinepräparaten mit verschiedenen Scoring-Modellen [82, 83, 84, 85], doch wurde bislang kein Konsens erzielt.

Die prognostische Bedeutung von TILs bei primärem NSCLC wurde in zahlreichen Studien bei Patienten mit reseziertem NSCLC untersucht. Dagegen wurden nur wenige Studien mit Patienten mit fortgeschrittenem NSCLC veröffentlicht, da die Routine-HE-Färbung (anstatt IHC) zur Beurteilung der Lymphozyten-Infiltration wegen des in diesem Setting verfügbaren geringen Biopsiematerials schwierig ist $[84,85]$. Eine hohe TIL-Dichte
310

Kompass Pneumol 2020;8:300-317 DOI: $10.1159 / 000511444$ 
war im pathologischen Stadium I [84] und III [85] mit einem längeren Überleben assoziiert. In einer großen italienischen Kohortenstudie mit 1290 Patienten fand sich ein Überlebensvorteil bei Patienten mit hoher TIL-Infiltration in der Plattenepithelkarzinom (squamous cell carcinoma, SCC)-Histologie, wohingegen in der Kohorte als Ganzes keine Assoziation mit dem Überleben beobachtet wurde. Diese Ergebnisse standen im Widerspruch zu einer kürzlich von Brambilla et al. veröffentlichten großen NSCLCStudie, in der bei allen histologischen Subtypen ein Überlebensvorteil erreicht wurde [82].

Bis jetzt ist CD8+ der robusteste prognostische TIL-Marker bei NSCLC [86, 87]. Tatsächlich besteht eine starke Assoziation zwischen einer ausgedehnten Stroma-Infiltration durch CD8-positive TILs und dem Überleben der Patienten. Hinsichtlich des prognostischen Einflusses von CD4-positiven TILs bei NSCLC wurden demgegenüber keine schlüssigem Ergebnisse erzielt [80, 88] und von den CD4-positiven Untergruppen waren Th1-Lymphozyten mit einem verlängerten Überleben assoziiert, während Th2-Lymphozyten mit einer Progression des Tumors assoziiert waren $[89,90]$. Eine Überexpression von CD45RO+ durch die TILs war mit verbesserten Outcomes bei verschiedenen Krebsarten sowie bei NSCLC assoziiert [91]; eine hohe Infiltration von FOXP3-positiven Tregs war dagegen mit einer schlechten Überlebensrate bei NSCLC korreliert [92].

Erste Beobachtungen bei Patienten mit rezidivierenden Krebserkrankungen deuten darauf hin, dass das klinische Ansprechen auf Immuncheckpoint-Blocker mit erhöhten tumoralen Konzentrationen von immuninhibitorischen Signalen, wie PD-L1, dem zytotoxischen T-Lymphozyten-assoziierten Protein 4 (CTLA-4) sowie mit erhöhten TIL-Zahlen assoziiert ist. Tokito et al. analysierten retrospektiv die prädiktive Relevanz der PD-L1-Expression in Kombination mit der Dichte CD8-positiver TILs bei 74 NSCLC-Patienten im Stadium III, die eine gleichzeitige Radiochemotherapie erhielten. Vier Patientengruppen wurden analysiert: «CD8+ high/PD-L1 neg», «CD8+ low/PD-L1 pos», «CD8+ high/PD-L1 pos» und «CD8+ low/PD-L1 neg». Bei einer medianen Follow-up-Dauer von 53 Monaten war das beste Outcome hinsichtlich PFS und OS in der Gruppe «CD8+ high/PD-L1 neg» (Median nicht erreicht) zu beobachten, gefolgt von der Gruppe «CD8+ high/PD-L1 pos» mit einem PFS von 17,6 Monaten und einem OS von 35,3 Monaten. Dagegen zeigte die Gruppe «CD8+ low/PD-L1 pos» mit einem PFS von 8,6 Monaten und einem OS von 13,9 Monaten die schlechtesten Outcomes. Diese Ergebnisse unterstreichen die negative prognostische Aussagekraft von PDL1 und heben die Bedeutung der Schnittstelle von Lymphozyten und Tumor hervor. Es ist bekannt, dass die Strahlentherapie zu einer erhöhten Expression von PD-L1 führt und die antitumorale Immunität fördert [93], daher ist berechtigterweise davon auszugehen, dass im Zeitalter der Immuntherapie die Kombination von PD-L1- und CD8-Expression eine bedeutsame prädiktive Aussagekraft in Hinblick auf das Ansprechen hat [94].

In allen Studien mit den PD-1-ICIs Nivolumab und Pembrolizumab lag der Schwerpunkt auf der tumoralen PD-L1-Expression als prädiktiver Biomarker, während die prädiktive Rolle der TILs nicht berücksichtigt wurde [1-3]. Studien mit dem PD-L1-Inhibitor Atezolizumab bestätigten demgegenüber die prädiktive Rolle der PD-L1-Expression auf Tumorzellen, berücksichtigten jedoch auch die PD-L1-Expression auf TILs. Durch diese Analyse wurde die prädiktive Bedeutung der TILs in diesem Setting validiert [4]. In einer Originalarbeit entwickelten Roger Sun et al. eine CT (Computertomographie)-basierte radiomische Signatur der tumoralen Immuninfiltration (CD8-positive Zellen) und analysierten ihre Korrelation mit den Outcomes von Patienten, die eine Immuntherapie erhielten. Dazu entwickelten und validierten sie zunächst eine radiomische Signatur für insgesamt 135 Patienten mit fortgeschrittenen soliden Tumoren in vier unabhängigen Kohorten, indem sie kontrastverstärkte CT-Aufnahmen und genomische RNA-seq-Daten aus Tumorbiopsien kombinierten und die Tumorinfiltration durch CD8-positive Zellen beurteilten. Die genomischen Daten basierten auf dem CD8B-Gen, wodurch es möglich war, die Zahl der CD8-Zellen in den Proben abzuschätzen. Die klinische Validierungskohorte umfasste 137 Patienten, die am Gustave-Roussy-Krankenhaus rekrutiert wurden und im Rahmen der MOSAICO-Studie eine Anti-PD-1- und Anti-PD-L1Monotherapie erhalten hatten. Bei diesen Patienten war ein hoher radiomischer Ausgangsscore mit einem höheren Anteil an objektivem Ansprechen nach 3 Monaten $(p=0,049)$ und einem verlängerten Gesamtüberleben in univariaten (medianes Gesamtüberleben 24,3 Monate vs. 11,5 Monate in der Gruppe mit niedrigem radiomischen Score, $\mathrm{p}=0,0081)$ und multivariaten Analysen $(\mathrm{p}=$ 0,0022) assoziiert. Dieser Algorithmus stellt einen vielversprechenden Weg zur Vorhersage des Immunphänotyps dar. Außerdem könnte er für die Schätzung der Zahl CD8-positiver Zellen und für die Vorhersage der klinischen Outcomes von Patienten, die mit Immuntherapie behandelt werden, von Nutzen sein; allerdings sind dafür weitere prospektive randomisierte Studien erforderlich [95].

Die prognostische Bedeutung der TILs bei NSCLC hat sich bestätigt und sie scheinen ein prädiktiver Faktor zu sein. Insbesondere die Kombination der CD8+- und PD-L1-Expression scheint ein robusterer Biomarker zu sein als PD-L1 allein. Eine direkte Bewertung der TILs bleibt jedoch schwierig, da zum einen die Menge an histologischem Material, das aus einer Biopsie gewonnen wird, gering ist, und zum anderen, weil eine einzelne bioptische Probe nicht das Mikromilieu der einzelnen Metastasen widerspiegelt. Dennoch kann die Einführung der radiomischen Immuninfiltrationssignatur eine valide, nicht invasive Methode zur Bewertung der TILs und zur Definition ihrer Bedeutung als Biomarker sein.

\section{Neu aufkommende Biomarker}

\section{T-Zell-Klonalität}

Die der Resistenz gegen ICIs zugrunde liegenden molekularen Mechanismen sind nicht vollständig verstanden. In neueren Untersuchungen lag das Hauptaugenmerk auf dem Repertoire an TZell-Rezeptoren (TCR) im peripheren Blut. Durch die Antigenerkennung werden antigenreaktive T-Zellen aktiviert, die prolife- 
rieren, und dieser Prozess führt zu einer klonalen Expansion [96] Bei Krebspatienten ist die Tumorerkennung durch T-Zellen gestört [97]. Dennoch reagieren tumorspezifische T-Zellen auf Tumorantigene, darunter auch individuelle «Neoantigene», die aus mutierten Proteinen in Krebszellen stammen [34, 98, 99, 100]. Allerdings können diese tumorspezifischen T-Zellen anerg bleiben [98]. T-Zell-Klone lassen sich durch die Bestimmung von TCR-Rearrangements nachverfolgen, die aus Genen der variablen (V)-Diversity (D)-Joining (J) Region bestehen, welche die antigenspezifische komplementaritätsbestimmende Region 3 (CDR3) hervorbringen. Die Analyse der T-Zell-Klonalität kann daher das Ausmaß der tumorantigen-getriebenen T-Zell-Expansionen aufzeigen und helfen, die Mechanismen zu offenzulegen, die der TZell-Toleranz gegenüber Krebsantigenen zugrunde liegen. Die Reaktivität der von TILs exprimierten TCRs bestimmt ihre Fähigkeit, mit Tumorantigenen, die auf Antigen-präsentierenden Zellen (APCs) präsentiert werden, in Wechselwirkung zu treten. Es liegen entsprechende Berichte vor, denen zufolge das TCR-Repertoire bei Krebspatienten mit einem Ansprechen auf die Immuncheckpoint-Blockade und mit dem Überleben assoziiert ist $[101,102]$. Bei Patienten, die gut auf die Immuntherapie ansprachen, waren vor Einleitung der CTLA4-Blockade T-Zell-Antworten gegen bestimmte Tumorantigene nachweisbar [103]. Eine dichte CD8+-T-Zell-Infiltration in das Tumormikromilieu korrelierte mit einer besseren Prognose unter PD-1-Hemmung [101]. Reuben et al. beschrieben kürzlich in einer Arbeit das T-Zell-Repertoire im Gewebe bei lokalisiertem NSCLC. Ihre Ergebnisse deuteten auf einen positiven Zusammenhang zwischen T-ZellDichte und -Klonalität hin. Ferner wiesen Tumoren mit hoher PD-L1 eine hohe T-Zell-Dichte und -Klonalität auf, und die TMB korrelierte zudem mit einer hohen T-Zell-Klonalität. Tatsächlich fand sich bei EGFR-mutiertem NSCLC eine geringere T-Zell-Klonalität, und dies könnte eine mögliche Erklärung für die geringere Wirksamkeit von ICIs bei diesen Patienten sein [104]. Seit Kurzem gelten T-Zell-Klon-Analysen als hilfreich für die Frühdiagnose von immunbezogenen unerwünschten Ereignissen (Immun-related Adverse Events, IrAEs). Mit Hilfe der Next-Generation-Sequenzierung wurde gezeigt, dass Patienten mit einem schweren IrAE unter einem CTLA4-Inhibitor eine höhere Anzahl von T-Zell-Klonen aufwiesen, die nach der Behandlung expandierten, noch bevor klinische Symptome eines IrAEs auftraten [105-107]. Bei Patienten, die schwere IrAEs entwickelten, wurden die CD4+- und CD8+-TCR-Spectratypes während der AntiCTLA4-Behandlung stärker eingeschränkt, was dafür spricht, dass neu expandierte oligoklonale T-Zell-Reaktionen möglicherweise an immunbezogenen unerwünschten Ereignissen beteiligt sind [108]. Arakawa et al. wiesen verschiedene T-Zell-Klone im Blut von Melanompatienten vor der Immuntherapie nach und dies könnte das Ausmaß widerspiegeln, in dem T-Zellen in der Lage sind, gegen das Melanom zu reagieren und möglicherweise die Progression des Melanoms zu kontrollieren. Daher könnte die T-Zell-Klonalität im Blut eine prädiktive Aussagekraft für das antitumorale Ansprechen unter der Checkpoint-Inhibition haben [108]. Hogan et al. bestimmten bei Melanompatienten, die eine
Anti-CTLA4- oder Anti-PD1-Therapie erhielten, vor der Behandlung die Evenness (Äquität) der kombinatorischen Diversität des TCR-Repertoires in peripheren mononukleären Zellen. Die Beurteilung der Ausgangs-Diversität des TCR-Repertoires im peripheren Blut könnte helfen, das Ansprechen auf Anti-PD1- und AntiCTLA4-Therapien vorherzusagen [109]. Ferner wiesen Postow et al. nach, dass die Ausgangs-Diversität des TCR-Repertoires im peripheren Blut bei Melanompatienten zudem mit dem klinischen Outcome assoziiert war [110]. Miyauchi et al. zeigten, dass die geringe klonale T-Zell-Expansion bei EGFR-mutiertem NSCLC ein entscheidender Faktor im Zusammenhang mit dem ungünstigen Ansprechen auf ICI sein könnte. Darüber hinaus könnte die TCR-Sequenzierung für die Therapieauswahl bei Patienten mit EGFR-Mutationen zur Anwendung kommen, indem die Anteile der TCR $\beta$-Klone im Tumor beurteilt werden. Trotz dieser Erkenntnisse ist es schwer zu beurteilen, ob T-Zell-Repertoires im Blut eine potenzielle prognostische Aussagekraft haben oder nicht.

\section{PTEN-Inaktivierung}

Das Tumorsuppressorgen PTEN (Phosphatase and tensin homolog deleted on chromosome 10) ist ein Schlüssel-Tumorsuppressorgen auf Chromosom 10q23, das erstmals 1997 identifiziert wurde [111]. Das PTEN-Protein wird ubiquitär exprimiert und fungiert als Phosphatase. Durch die Dephosphorylierung von PIP3 zu PIP2 bewirkt PTEN letztlich eine Hemmung des PI3K/ mTOR/Akt-Signalweges, einem Hauptpfad, über den Wachstum, Überleben und Migration der Zelle reguliert werden [112]. Anders als die anderen Tumorsuppressorgene wie Retinoblastoma Transcriptional Corepressor 1 (RB1) [113] oder Adenomatous Polyposis Coli (APC) [114], die hinsichtlich ihrer Inaktivierung der Two-Hit-Hypothese von Knudson folgen [115], wird die PTENFunktion nachgewiesenermaßen bereits durch eine mäßige Verringerung ihres Expressionsniveaus beeinträchtigt, so dass es sich in der Folge wie ein Suszeptibilitätsgen für die Entstehung von Krebs verhält [116]. Neben der negativen Regulation des onkogenen PI3K/mTOR/Akt-Signalwegs spielt PTEN auch im DNA-Reparaturprozess und bei der Aufrechterhaltung der chromosomalen Integrität eine Rolle [117].

Über die Beteiligung von PTEN bei Lungenkrebs wurde weithin berichtet, obgleich genetische Veränderungen wie Mutationen und Deletionen mit einer Häufigkeit von 2-7\% der Fälle nicht das wichtigste wiederkehrende Ereignis sind [118]. Der Verlust des PTEN-Proteins ist dagegen häufiger zu beobachten. Er betrifft etwa 40\% der Lungenkrebspatienten und korreliert mit der Raucheranamnese, dem Plattenepithel-Histotyp sowie einer kürzeren Überlebensdauer [118]. Interessanterweise wurde der Verlust der PTEN-Aktivität auch mit der Resistenz gegen zielgerichtete Therapien sowie gegen Immuntherapien in Verbindung gebracht. In diesem Zusammenhang beschrieben Peng und Kollegen kürzlich ein komplexes Zusammenspiel zwischen der Regulation onkogener Signalwege, wie beispielsweise über PTEN, und dem Ansprechen auf eine Immuntherapie in präklinischen Modellen zum Melanom [119]. Die Autoren nannten eine Resistenz gegen
312

Kompass Pneumol 2020;8:300-317 DOI: $10.1159 / 000511444$ 
die T-Zell-vermittelte Immuntherapie als mögliche Folge des PTEN-Verlusts und berichteten, dass dieser mit einer verminderten T-Zell-Infiltration in den Tumorlokalisationen sowie mit einem schlechteren Outcome bei Melanompatienten, die eine AntiPD-1-Therapie erhielten, korrelierte. Interessanterweise verbesserte sich die Wirksamkeit von Immuncheckpoint-Inhibitoren bei Mäusen, die mit einem selektiven PI3K $\beta$-Inhibitor behandelt wurden, was dafürspricht, dass der PTEN-Verlust möglicherweise durch Hochregulation des PI3K/mTOR/Akt-Signalwegs die Immunresistenz fördert. Daher lohnt es sich, Kombinationen von Immuntherapie und Inhibitoren des PI3K-Akt-Signalwegs näher zu untersuchen [119].

Die Beteiligung von PTEN beim Ansprechen auf die Therapie mit Immuncheckpoint-Blockern wurde 2016 auch bei Lungenkrebs untersucht [120]. Dabei integrierten die Autoren Daten von $\mathrm{Mu}-$ tationsprofilen und tumorinfiltrierenden Zellen von 113 Patienten im fortgeschrittenen Stadium, die Anti-CTLA-4/PD-1 erhielten. Hervorzuheben ist, dass sich PTEN-Mutationen nur bei NonRespondern fanden, was die mögliche Bedeutung dieses Tumorsuppressor-Gens für die Immunresistenz auch bei Lungenkrebs stützt.

\section{POLE-Mutationen}

Die katalytische Untereinheit A der DNA-Polymerase-epsilon (POLE) ist ein breit exprimiertes Gen auf Chromosom 12q24.33 und eine von vier Untereinheiten, die die DNA-Polymerase-Epsilon (Pole) bilden. Bei dieser handelt es sich um einen Enzymkomplex, der für die Synthese des führenden DNA-Strangs während der DNA-Replikation verantwortlich ist. POLE ist die wichtigste katalytische und korrekturlesende ("proofreading») Untereinheit von Pole und sie besitzt die Fähigkeit zur Replikation sowie 3'-5'-Exonukleaseaktivität. Daher ist dieses Enzym sowohl an der DNA-Replikation als auch an den Signalwegen der DNA-Reparatur beteiligt, die für die High-Fidelity-Aktivität zur Verhinderung der Tumorentstehung von zentraler Bedeutung sind [121]. Berichten zufolge sind Mutationen in der Korrekturdomäne von POLE pathogen und führen zu einer etwa 100-fachen Steigerung der Mutationsrate und dadurch zu einem Anstieg der Tumormutationslast (TMB). Tumoren, die POLE-Mutationen tragen, werden daher allgemein als «ultramutiert» bezeichnet [122]. Diese Tumoren weisen eine erhöhte Neoantigenlast und tumorinfiltrierende Lymphozyten auf und sprechen möglicherweise besser auf eine Immuntherapie an $[123,124]$.

POLE-Mutationen wurden bei 7-12\% der Endometriumkarzinome und bei 1-2\% der kolorektalen Karzinome sowie bei anderen Tumoren [125, 126], einschließlich NSCLC [127, festgestellt 128]. Interessanterweise haben Endometriumkarzinome mit somatischen Mutationen der POLE-Proofreading-Domäne eine ausgezeichnete Prognose, die wahrscheinlich durch die hohe Zahl von antigenen Neoepitopen bedingt ist, die in der Lage sind, eine starke antitumorale Immunantwort zu stimulieren [125]. Kürzlich erschienenen Berichten zufolge sollte die Vorhersage eines hervorragenden Outcomes bei Patientinnen mit Endometriumkarzinom jedoch auf Fälle beschränkt sein, die Hotspot-POLE-Muta- tionen tragen, wohingegen Mutationen mit unbekannter Signifikanz weiter untersucht werden sollten [129]. Die Häufigkeit von POLE-Mutationen bei NSCLC-Patienten wurde 2018 mittels Next-Generation-Sequenzierung untersucht. Die Untersuchung ergab, dass 9 von 319 Patienten (2,8\%) eine POLE-Mutation aufwiesen. Interessanterweise war bei Lungen-Adenokarzinomen mit POLE-Mutation die mediane TMB um das 1,6-fache pro Mb ( $p=0,026$ ) erhöht, und sowohl die PD-L1-Expression als auch die CD8-positiven tumorinfiltrierenden Lymphozyten fielen in dieser Subgruppe von NSCLC-Patienten höher aus, was für die POLE-Mutation als Biomarker-Kandidaten zur Vorhersage des Ansprechens auf eine Immuntherapie spricht [127]. Parallel dazu untersuchten Liu et al. [128] eine Kohorte von 513 Patienten mit einem Adenokarzinom der Lunge und 497 Patienten mit einem Plattenepithelkarzinom aus dem Cancer Genome Atlas (TCGA), um die prognostischen Aussagekraft der POLE-Mutationen und der PD-L1-Expression zu testen. In den Patientenkohorten waren 6\% der Patienten mit Adenokarzinom bzw. 5,6\% der Patienten mit Plattenepithelkarzinom positiv für eine POLE-Mutation. Den Ergebnissen zufolge waren POLE-Mutationen nur bei Patienten mit Plattenepithelkarzinom ein günstiger Biomarker für ein verlängertes OS ( $p=0,033)$, obgleich Adenokarzinome mit POLE-Mutation und hoher PD-L1-Expression ebenfalls ein verlängertes OS zeigten ( $p=0,024)$. Dieser Benefit wurde mit der Aktivierung der Signalwege für die antitumorale Immunantwort in Verbindung gebracht und nicht mit dem Vorhandensein von tumorinfiltrierenden Lymphozyten [128].

Fazit: Lungenkrebspatienten können ebenfalls POLE-Mutationen tragen und diese werden in Zukunft möglicherweise Bestandteil von Biomarker-Panels sein, die darauf abzielen vorherzusagen, welche Patienten von einer Therapie mit Immuncheckpoint-Inhibitoren profitieren würden.

\section{Lymphozyten-Verhältnis}

In verschiedenen Studien wurde die Hypothese aufgestellt, dass bei NSCLC-Patienten, die eine Immuntherapie erhalten, eine Assoziation zwischen der Zahl der peripheren Blutzellen vor der Behandlung und dem Outcome bestehen könnte, insbesondere im Hinblick auf die Lymphozyten und das Verhältnis von Neutrophilen zu Lymphozyten (Neutrophile/Lymphozyten-Quotient, neutrophil-to-lymphocyte ratio, NLR).

Einige retrospektive Fallserien [130-134] deuteten auf einen $\mathrm{Zu}$ sammenhang zwischen einem hohen NLR-Ausgangswert und schlechteren Outcomes unter einer Immuntherapie mit ICIs hin. Dieses Ergebnis wurde durch einige kleine prospektive Studien bestätigt $[135,136]$. Die jeweiligen Serien ergaben, dass ein erhöhter NLR-Wert, HLA-DRlow-Monozyten und eine niedrige Zahl dendritischer Zellen mit einem kürzeren OS und PFS assoziiert waren [135], und dass ein erhöhter NLR-Wert und ein erhöhtes Verhältnis von Thrombozyten zu Lymphozyten (Thrombozyten/ Lymphozyten-Quotient, platelet-to-lymphocyte ratio, PLR) mit einem kürzeren OS und PFS sowie mit einer niedrigeren Ansprechrate assoziiert waren [136]. Ob es sich bei dem NLR-Wert wirklich um einen prädiktiven oder prognostischen Faktor han- 
delt, ist jedoch weiterhin unklar. Tatsächlich wurde der NLR in den Gustave-Roussy-Immun-Score, einen validierten prognostischen Score für Patienten in Phase-I-Studien zur Immuntherapie, aufgenommen [137].

Keine der oben genannten Studien beinhaltete darüber hinaus einen Kontrollarm. Russo et al. [138] führten eine Studie durch, an der 23 mit Nivolumab behandelte NSCLC-Patienten und 27 NSCLC-Patienten, die Docetaxel erhielten, als Kontrollen teilnahmen: Neutrophilie, Thrombozytose und ein hoher abgeleiteter NLR bei Baseline waren mit einem fehlenden Ansprechen (ORR: 0\%) sowohl auf Nivolumab als auch auf Docetaxel assoziiert; ein erhöhter PLR war zudem mit einem verminderten Ansprechen auf Nivolumab und fehlendem Ansprechen auf Docetaxel assoziiert.

In einer anderen Studie [139] wurde ein Zusammenhang zwischen der klinischen Wirksamkeit der Atezolizumab-Therapie und Veränderungen des Lymphozytenverhältnisses nachgewiesen, doch keiner der Ausgangswerte korrelierte mit den Outcomes.

In einer Kohorte von 31 Patienten, die Nivolumab erhielten, war die absolute Zahl der zirkulierenden NK-Zellen bei Baseline in der Gruppe mit klinischem Benefit (partielles Ansprechen, komplettes Ansprechen oder stabile Erkrankung) doppelt so hoch wie in der Gruppe der Patienten, die nicht auf die Therapie ansprachen [140]; diese Ergebnisse wurden anschließend durch die Beurteilung der Receiver Operating Characteristic (ROC)-Kurve, die eine hohe Sensitivität und Spezifität zeigte, approximiert. Wie oben erläutert, haben die verschiedenen Lymphozytenquotienten den Vorteil, dass sie leicht zu berechnen und minimal invasiv sind; allerdings haben sie eher eine prognostische Bedeutung als eine prädiktive Aussagekraft für das Ansprechen auf ICIs gezeigt. Es ist wahrscheinlich, dass sie als objektive Daten in komplexere Scores zur Prognosebewertung einbezogen werden können.

\section{Co-Mutation von KRAS und STK11}

Die Gene der RAS-Familie kodieren für kleine Guanosintriphosphatase (GTPase)-Proteine, von denen K-ras, H-ras und N-ras am besten bekannt sind. Durch ihre Aktivierung kommt es zur Übertragung von Signalen an verschiedene biochemische Signalwege wie RAF-MEK-ERK, PI3K-AKT-mTOR und RALGDS-RA, welche die Proliferation, Differenzierung, Motilität und Apoptose der Zelle steuern. Somatische aktivierende Mutationen des KRAS-Gens sind beim NSCLC am häufigsten zu beobachten, insbesondere beim Adenokarzinom der Lunge (etwa 20-30\%) und seltener beim Plattenepithelkarzinom (etwa 5\%) [141]. Die häufigsten Mutationen treten in den Codons 12 und 13 auf; sie sind mit Zigarettenrauchen assoziiert und gehen im Vergleich zum KRAS-Wildtyp mit einer ungünstigen Prognose einher [142]. Neuere Studien wiesen mithilfe von Gen-Expressions-Profiling nach, dass KRAS-Mutationen sich in der Regel, jedoch nicht immer, mit EGFR-Mutationen oder EML4-ALK-Rearrangement gegenseitig ausschließen $[35,143,144]$ und nur selten in der Lage sind, mit anderen genomischen Veränderungen zu koexistieren [145]. Eine große Analyse, in der 1343 NSCLC-Tumorproben mit- tels NGS untersucht wurden, ergab eine signifikante Assoziation zwischen EGFR- und PI3KCA- oder CTNNB1-Mutationen sowie zwischen KRAS- und STK11-Mutationen [146]. Das STK11-Gen kodiert insbesondere für eine Serin/Threonin-Kinase 11, die sogenannte Leberkinase B1 (LKB1), die eine direkte Phosphorylierung und Aktivierung einer AMP-aktivierten Proteinkinase (AMPK) bewirkt - ein metabolischer Checkpoint, von dem bekannt ist, dass er den Lipid-, Cholesterin- und Glukosestoffwechsel in spezialisierten metabolisch aktiven Geweben wie Leber, Muskel und Fettgewebe reguliert [147]. Einer der wichtigsten wachstumsregulierenden Signalwege, die durch LKB1-AMPK kontrolliert werden, ist verschiedenen Arbeiten zufolge der mTOR (mammalian target-of-rapamycin)-Signalweg. Dieser kontrolliert das Zellwachstum in allen Eukaryonten und ist bei den meisten menschlichen Krebsarten fehlreguliert [148-150]. Somatische Mutationen von STK11/LKB1 finden sich bei verschiedenen malignen Tumoren, darunter auch NSCLC, bei dem sie bei bis zu 30\% der Patienten vorhanden sein können, wobei sie beim Adenokarzinom häufiger sind als beim Plattenepithelkarzinom [151, 152]. Darüber hinaus wurde gezeigt, dass gleichzeitige Mutationen der KRAS- und STK11-Gene bei Patienten mit Adenokarzinom der Lunge mit einer schlechten Überlebensdauer einhergehen [153]. Ihre Rolle im Zusammenhang mit dem Ansprechen auf verschiedene Arten von Behandlungen, einschließlich Immuntherapie, muss jedoch noch weiter untersucht werden.

Eine kürzlich durchgeführte große Subgruppenanalyse von NSCLC-Patienten mit KRAS-Mutation, die im Rahmen des italienischen erweiterten Zugangsprogramms mit Nivolumab behandelt wurden, zeigte klar, dass Nivolumab bei Patienten mit KRASMutation im Vergleich zu KRAS-Wildtyp-Patienten weder die ORR, noch das PFS oder OS verbesserte (ORR: $20 \%$ vs. $17 \%$; medianes PFS: 4 vs. 3 Monate; medianes OS: 11,2 vs. 10 Monate), wobei die 3-Monats-PFS-Rate bei Patienten mit KRAS-Mutation allerdings signifikant länger war als bei KRAS-Wildtyp-Patienten (53\% vs. $42 \%)$ [154]. Da die Inaktivierung von STK11 durch mutationsbezogene oder nicht mutationsbezogene Mechanismen mit einem inerten tumoralen Immunmikromilieu und einer geringen PD-L1-Expression assoziiert ist $[155,156]$, wurde vermutet, dass gleichzeitig auftretende KRAS- und STK11 (KRAS/ STK11)-Veränderungen bei Patienten mit NSCLC mit einem schlechteren Ansprechen auf ICIs assoziiert waren. In einer retrospektiven Analyse von Skoulidis und Kollegen, die 174 mit Nivolumab behandelte Patienten mit einem KRAS-mutierten Adenokarzinom der Lunge einschloss, fand sich eine signifikant niedrigere ORR bei Patienten mit STK11-Veränderungen als bei Patienten mit TP53-Veränderungen (7,4\% vs. 35,7\%). Die Autoren bestätigten diese Beobachtung durch Vergleich der ORR zwischen den beiden Subgruppen in der randomisierten klinischen Phase-3-Studie CheckMate057 (ORR = 0\%, 0/6 vs. 57,1\%, 4/7) und in der GEMINI-Studie (ORR $=0 \%, 0 / 6$ vs. 53\%, 9/17) [67]. Ähnliche Ergebnisse wurden in einer Kohorte von Patienten, die im Rahmen der CheckMate-012-Studie Nivolumab plus Ipilimumab erhielten, festgestellt (ORR $=0 \%, 0 / 3$ für KRAS/STK11 vs. 78\%, 7/9 für KRAS/TP53) [157]. Zudem waren das PFS und OS bei Pa-
314

Kompass Pneumol 2020;8:300-317 DOI: $10.1159 / 000511444$ 
tienten mit KRAS/STK11-Co-Mutation im Tumor signifikant kürzer als bei Patienten mit KRAS-mutiertem Tumor und STK11Wildtyp (KRASm/STK11wt) (PFS: p < 0,001; OS: p = 0,0015) [67] Zwar weisen Tumoren mit KRAS/STK11-Mutation gegenüber KRASm/STK11wt-Tumoren eine geringere PD-L1-Expression auf, doch war das Auftreten von Mutationen unabhängig von der PD-L1-Expression. Außerdem wurde die Assoziation der STK11Mutation mit einem schlechteren klinischen Outcome auch bei der PD-L1-positiven Subgruppe von Patienten mit KRAS/STK11mutiertem NSCLC, die mit ICIs behandelt wurden, bestätigt [67]. Koyama et al. zeigten im Mausmodell zum NSCLC mit KRASDrivermutation, dass die Co-Mutation von STK11 zu einer Akkumulation von Neutrophilen mit T-Zell-suppressiven Effekten sowie zu einer erhöhten Expression von Markern der T-Zell-Erschöpfung und von immunsuppressiven Zytokinen führte. Ferner war die Anzahl der TILs verringert, und schließlich wurde auch eine verminderte Expression von PD-1-Ligand PD-L1 beschrieben [158].

Kürzlich zeigte eine andere Arbeit, dass NSCLC-Patienten mit KRAS/STK11-Co-Mutation, die ICIs als Second- oder ThirdLine-Therapie erhielten, ein schlechteres PFS und OS aufwiesen als Patienten, bei denen nur eine STK11-Mutation vorlag (medianes PFS: 2,4 Monate vs. 5,1 Monate, $\mathrm{p}=0,048$; medianes OS: 7,1 Monate vs. 16,1 Monate, $\mathrm{p}<0,001)$ [159].

Insgesamt sprechen diese Daten dafür, dass die STK11/LKB1-Mutation ein wichtiger Treiber für die Immunevasion ist und dass eine gleichzeitig auftretende KRAS/LKB1-Mutation ein potenzieller Biomarker für einen eingeschränkten klinischen Benefit durch ICIs bei fortgeschrittenem NSCLC sein könnte. Angesichts der begrenzten Menge verfügbarer Daten sind jedoch weitere Studien zur Bewertung der Auswirkungen der KRAS/STK11-CoMutation als Reaktion auf eine Immuntherapie erforderlich.

\section{IFN-gamma und JAK/STAT-Achse}

Hinsichtlich der Expression von Interferon gamma (IFN- $\gamma$ ) und seiner prognostischen und prädiktiven Aussagekraft für das Ansprechen auf die Immuntherapie wurden zahlreiche Hypothesen aufgestellt.

Bei Krebs wird IFN- $\gamma$ hauptsächlich von TILs in Form von TZellen und NK-Zellen gebildet [160]. Dieses Protein kann die PD-L1-Expression heraufregulieren. In der Tat zeigte eine kürzlich durchgeführte Studie mit 21 Melanompatienten und 17 NSCLC-Patienten, die mit Nivolumab behandelt wurden, dass eine hohe Expression von IFN- $\gamma$-mRNA in beiden Gruppen mit einem längeren PFS und OS assoziiert war; allerdings erreichte der OS-Unterschied bei den NSCLC-Patienten keine statistische Signifikanz [161]. Andere ähnliche Studien zu verschiedenen soliden Tumoren, waren zwar durch eine kleine Stichprobengröße limitiert, bestätigten jedoch, dass IFN- $\gamma$ möglicherweise ein guter prädiktiver Biomarker für das Ansprechen auf Anti-CTLA4oder Anti-PD-1/PD-L1 ICIs ist [12].

Die Begründung, die neben der direkten Heraufregulation von PD-L1/L2 stark für diese Hypothese spricht, basiert auf den nachgeschalteten IFN- $\gamma$-Signalwegen. Die Bindung von IFN- $\gamma$ an sei- nen Rezeptor hat eine Phosphorylierung von JAK1 und JAK2 sowie eine Dimerisierung von STAT1-2 zur Folge. Diese Dimere akkumulieren im Zellkern, wo sie über IRF1 als Transkriptionsfaktoren wirken, die letztlich zu einer erhöhten Expression von PD-L1 auf der Zelloberfläche führen [162, 163].

Derzeit laufen verschiedene klinische Studien, in denen die Expression von IFN- $\gamma$ mit verschiedenen Methoden (mRNA, Gensignaturen usw.) untersucht wird, mit dem Ziel, eine Standardmethode zu validieren, die in der täglichen klinischen Praxis einsetzbar ist.

\section{IL-6}

IL-6 ist ein proinflammatorisches Zytokin und wird von T-Zellen und Makrophagen gebildet, die normalerweise über einen mit IFN- $\gamma$ verbundenen Signalweg an der Tumorprogression und der Immunregulation beteiligt sind. Anders als IFN- $\gamma$ bewirkt dieses Zytokin eine Herunterregulation der Expression von PD-L1 und Klasse-I-HLA auf der Zelloberfläche und dies könnte ein Mechanismus für die Tumorevasion und -resistenz gegenüber der Behandlung mit ICIs sein [162].

Bjoern et al. [164] wiesen diesen Effekt beim Menschen nach und stellten fest, dass das Auftreten hoher IL-6-Spiegel unter einer Anti-CTLA4-Therapie in einer Kohorte von Melanompatienten mit einer schlechteren Prognose und einer Resistenz gegenüber der Behandlung assoziiert war.

In Hinblick auf NSCLC ergab eine prospektive Studie, dass ein hoher IL-6-Spiegel ein prognostischer Faktor für ein schlechtes OS, unabhängig von der Behandlung, ist [165].

\section{B7-H4}

Die V-Set-Domäne, die das Gen für den T-Zell-Aktivierungsinhibitor-1 enthält (Chromosom 1p13.1-p12) kodiert für das Protein B7-H4, ein Typ-I-Transmembranprotein, das zur Immunglobulin-Superfamilie B7 gehört. B7-H4 bewirkt eine negative Modulation der T-Zell-Funktion. Zwar ist sein Rezeptor noch nicht bekannt, doch liegen Hinweise vor, nach denen er auf aktivierten T-Zellen induziert werden kann. Die Bindung von B7-H4 an die T-Zellen hat einen starken inhibitorischen Effekt auf die Zellproliferation, die Interleukinsekretion sowie die Zytotoxizitätsaktivität [166-168]. Berichten zufolge spielt B7-H4 zudem eine bedeutsame Rolle bei der Entstehung und Progression von Krebs, indem es eine Hemmung der Apoptose bewirkt und die Proliferation, Migration und Invasion der Zellen beschleunigt [169]. Zhen-Ye Li et al. [170] untersuchten die B7-H4-Expression in Hirnmetastasen von NSCLC und berichteten, dass das mediane OS bei Patienten, deren Metastasen stark positiv für die B7-H4Expression waren, kürzer ausfiel als bei Patienten mit niedriger B7-H4-Expression (11,4 Monate vs. 26,2 Monate; p = 0,002) [170]. Aufgrund der negativen Modulation der T-Zellen wurde B7-H4 darüber hinaus als ein Prädiktor für das Ansprechen auf die Immuncheckpoint-Blockade diskutiert. Genova et al. führten kürzlich eine Pilotstudie durch, in der sie die B7-H4-Proteinexpression in einer Kohorte von 46 mit Nivolumab behandelten Patienten mit fortgeschrittenem NSCLC analysierten. Hervorzuheben ist, 
dass Patienten mit B7-H4-positivem Tumor (Cut-off-Wert $>1 \%$ der Tumorzellen) ein mehr als zweifach erhöhtes Risiko für eine Krankheitsprogression und einen tumorbedingten Tod aufwiesen als B7-H4-negative Patienten [171].

\section{Exosomen}

Bei Exosomen handelt es sich um extrazelluläre Vesikel mit einer Größe zwischen 40 und 100 nm. Diese kleinen Vesikel, die während der endosomalen Reifung freigesetzt werden, enthalten Biomoleküle wie genetisches Material, einschließlich DNA, mRNAs, miRNAs und andere nicht kodierende RNAs, sowie Proteine [172]. Exosomen sind in verschiedenen Körperflüssigkeiten wie Blut, Sputum, Urin oder malignen Ergüssen zu finden und spielen eine entscheidende Rolle bei der interzellulären Kommunikation [173]. Interessanterweise können aus Tumoren stammende Exosomen mit ihrem molekularen und genetischen Inhalt die Zusammensetzung von Tumorzellen widerspiegeln. Es liegen zunehmend Hinweise vor, nach denen aus Tumoren stammende Exosomen Tumorzellen retten können, indem sie sich der Überwachung durch Immunzellen entziehen, und dies könnte ein therapeutischer Angriffspunkt sein [174]. Tatsächlich sind aus Tumoren stammende Exosomen in der Lage, die Funktion von Immunzellen zu unterdrücken, indem sie ihren Inhalt transferieren und so die Krankheitsprogression bei Lungenkrebs steuern [175]. Neueren Hinweisen zufolge tragen Exosomen aus verschiedenen Tumorzellen, darunter auch Lungenkrebszellen, immunsuppressiv wirkenden PD-L1 auf ihrer Zelloberfläche. Dieser kann durch IFN- $\gamma$ heraufreguliert werden, wodurch es zu einer Unterdrückung der Funktion von CD8-positiven T-Zellen und der Immunantwort kommt und das Tumorwachstum erleichtert wird [176, 177]. Insbesondere ist die Konzentration an zirkulierendem exosomalen PD-L1 bei Patienten mit metastasiertem Melanom positiv mit der IFN- $\gamma$-Konzentration korreliert und ändert sich im Verlauf der Anti-PD-1-Therapie. Exosomen können darüber hinaus mRNAs, die in Proteine übersetzt werden können, sowie regulatorische miRNAs transferieren [178]. In diesem Zusammenhang sind in Kohorten von Melanom- und NSCLC-Patienten Veränderungen der PD-L1-mRNA in den Exosomen unter der Behandlung mit Anti-PD-1-Antikörpern wie Nivolumab und Pembrolizumab beschrieben worden [179]. Insbesondere wurde eine signifikante Zunahme des PD-L1Transkripts in den Exosomen bei Patienten mit Krankheitsprogression festgestellt, und dies spricht dafür, dass die Überwachung der PD-L1-Expression in den Exosomen hilfreiche Informationen über das Ansprechen auf die ICI-Therapie liefern könnte. Neuere Daten zeigen zudem, dass in Exosomen eingebettete miRNAs an verschiedenen pathologischen Prozessen, wie etwa der Proliferation und Migration von Lungenkrebszellen, der Angiogenese und Progression [180] sowie am klinischen Ansprechen auf die Immuntherapie beteiligt sind. Peng und Kollegen führten kürzlich eine miRNA-Sequenzierung von PlasmaExosomen von 30 NSCLC-Patienten, die eine Immuntherapie erhielten, durch. Die Autoren identifizierten 3 Mitglieder der miRNA-320-Familie (miRNA-320b, miRNA-320c und miRNA- 320d) als potenzielle Biomarker für die Vorhersage der Wirksamkeit einer Immuntherapie bei fortgeschrittenen NSCLCs. Ferner wiesen die Autoren nach, dass miRNA-125b-5p im Exosomenplasma von Patienten mit partiellem Ansprechen nach der Behandlung gegenüber den Ausgangswerten herunterreguliert war [181].

Insgesamt lässt sich sagen, dass die genannten und andere Studien den Inhalt von Exosomen wie Proteine, mRNAs und miRNAs als aussichtsreiche diagnostische Biomarker und mögliche therapeutische Angriffspunkte bei Lungenkrebs und Immuntherapie zum Thema haben.

\section{TIS}

Derzeit verdichten sich die Hinweise, nach denen der entzündliche Phänotyp des Tumors mit dem Ansprechen auf die Immuntherapie korreliert $[182,183]$. Dementsprechend wurden verschiedene Genexpressionssignaturen, die mit dem Tumormikromilieu in Zusammenhang stehen, als prädiktive Marker für den klinischen Benefit von Patienten, die eine Anti-PD-1/PD-L1-Behandlung erhalten, beschrieben [171, 184-189]. Unter diesen identifizierten Ayers et al. [184] im Jahr 2017 ein 18-Gen-Profil, die sogenannte «Tumor Inflammation Signature» (TIS) mithilfe der digitalen Detektionstechnologie NanoString nCounter (NanoString Technologies, Inc., Seattle, WA, USA). Die TIS beinhaltete auf IFN- $\gamma$ reagierende Gene, die mit der Antigenpräsentation, der Chemokin-Expression, der zytotoxischen Aktivität und der adaptiven Immunresistenz in Zusammenhang stehen. Die Autoren führten eine strenge mehrstufige Validierung mit unabhängigen Patientenkohorten durch und schlugen einen TIS-Score vor, der durch eine gewichtete Kombination von 18-TIS-Genexpressionswerten ermittelt wird und in der Lage ist, das Ansprechen bei verschiedenen soliden Tumoren vorherzusagen. Danaher und Kollegen untersuchten kürzlich mit diesem TIS-Algorithmus den Immunphänotyp an 9000 aus dem Krebsgenomatlas (TCGA) heruntergeladenen Tumorexpressionsprofilen [176]. Auffällig war, dass ein hoher TIS-Score überwiegend mit Tumoren assoziiert war, die eine klinische Sensitivität gegenüber der Anti-PD-1-Blockade aufwiesen, wie Melanom, Lungentumoren, Nierenkarzinom und Tumoren im Gesichts- und Halsbereich. Zudem zeigte der TIS-Score bei den meisten Krebsarten eine minimale Korrelation mit der Mutationslast. Die Autoren untersuchten das Tumormikromilieu zur Beurteilung des inflammatorischen oder nicht inflammatorischen Phänotyps und vermuteten, dass der TIS-Score im Vergleich zur Mutationslast, welche die potentiell immunaktivierende Expression von Neoantigenen misst, Informationen über die adaptive Immunantwort innerhalb des Tumors liefern kann.

Insgesamt unterstreichen diese Ergebnisse, dass Genexpressionssignaturen, die den inflammatorischen Phänotyp des Tumors bewerten, indem sie mehrere Gene, die mit dem Mikromilieu des Tumors zusammenhängen, gleichzeitig bestimmen, das Wissen über den Immunstatus des Tumors erweitern können.
316

Kompass Pneumol 2020;8:300-317 DOI: $10.1159 / 000511444$ 


\section{Diskussion}

Die Suche nach Biomarkern, die in der Lage sind, das Ansprechen auf die Immuncheckpoint-Blockade vorherzusagen, gewinnt für die Patientenselektion zunehmend an Bedeutung. In der vorliegenden Arbeit haben wir die bekanntesten und neu aufkommende Biomarker vorgestellt. Trotz vielversprechender Ergebnisse wiesen alle beschriebenen Biomarker Einschränkungen hinsichtlich ihrer Fähigkeit auf, einen Patienten als Responder oder NonResponder auf eine Immuntherapie zu definieren. Dabei bestanden die Hauptschwierigkeiten in der intratumoralen Heterogenität und den dynamischen Veränderungen solcher Biomarker über die Zeit. Insbesondere wegen der unterschiedlichen Expression einiger dieser Biomarker innerhalb derselben Läsion oder zwischen verschiedenen Läsionen eines einzelnen Patienten ist die Biopsie-Entnahme zur Vorhersage des Ansprechens vergleichsweise unzuverlässig. Demgegenüber stellt sich angesichts der möglichen Veränderung der Expression einiger Biomarker im Zeitverlauf die Frage, ob die wiederholte Bewertung desselben Prädiktors während des Krankheitsverlaufs bei einem einzelnen Patienten hilfreich sein kann, um den bestmöglichen Zeitpunkt für den Beginn der ICI-Therapie zu ermitteln.

Ein weiterer kritischer Punkt im Zusammenhang mit der Biomarker-Analyse bei NSCLC ist die Schwierigkeit, adäquate Gewebeproben zu gewinnen, denn die Bewertung von gewebebasierten Biomarkern wird durch die relative Knappheit von bioptischem Material, das sich mithilfe der Standardverfahren gewinnen lässt, zusätzlich erschwert. Die Liquid Biopsy durch Blutentnahme ist potenziell in der Lage, diese Schwierigkeiten zu überwinden, und zudem möglicherweise eher repräsentativ für die systemische Expression eines bestimmten Biomarkers als die Gewebebiopsie. Außerdem ist peripheres Blut leicht zugänglich, was eine Bewertung der Veränderung im Zeitverlauf ermöglicht. Zwar besitzt die Flüssigbiopsie Potenzial, doch wird sie weiterhin durch einige Einschränkungen erschwert, die vor allem darin bestehen, dass ihre Sensitivität derzeit im Vergleich zu Tumorgewebe geringer ist und sie nicht für die Analyse spezifischer Histologie-basierter Biomarker, wie etwa TILs, eingesetzt werden kann.

Da sich das Behandlungsszenario bei fortgeschrittenem NSCLC durch die Anwendung von ICIs in der First-Line-Therapie schnell verändert, könnten sich robuste prädiktive Biomarker zudem als entscheidend für therapeutische Entscheidungen erweisen, insbesondere wenn es um zuverlässige negative prädiktive Faktoren geht, durch die es unter Umständen möglich ist, diejenigen Patienten auszuwählen, die nicht von der Behandlung mit einem ICI zusätzlich zu oder anstelle einer platinbasierten Chemotherapie als First-Line-Therapie profitieren, unabhängig von der PD-L1-
Expression. Ebenso könnten Patienten, die nicht auf eine ICI-Gabe als Second-Line-Therapie im Anschluss an eine platinbasierte Chemotherapie ansprechen, potenzielle Kandidaten für andere therapeutische Strategien sein, wie etwa Chemotherapie plus antiangiogene Wirkstoffe (z.B. Docetaxel plus Nintanib).

Unseres Erachtens sind einige deskriptive Biomarker, wie Auftreten, Dichte und Klonalität der T-Zellen, möglicherweise die aussichtsreichsten prädiktiven Biomarker für die zugelassene Behandlung. Ferner könnten einige der anderen in dieser Übersichtsarbeit beschriebenen Biomarker, wie STK11, INF $\gamma$, PTEN, Angriffspunkte für neuartige Medikamente darstellen, um die Resistenz gegen ICIs zu überwinden.

Und schließlich könnten sich im Zuge der Identifizierung neuer Biomarker einige dieser Moleküle selbst als mögliche therapeutische Ziele erweisen anstatt als Prädiktoren für den Benefit durch PD-1/PD-L1- oder CTLA4-ICIs. Dies könnte beispielsweise für B7-H4 gelten, für das derzeit ein spezifischer Inhibitor (FPA150) bei soliden Tumoren untersucht wird [190]. Als Fazit lässt sich sagen, dass ein umfassenderes Wissen über das tumorale Mikromilieu eine effizientere Selektion derjenigen Patienten ermöglichen könnte, die tatsächlich von ICIs profitieren, während es in naher Zukunft dazu führen könnte, dass die für den Patienten am besten geeignete Behandlungsstrategie ausgewählt wird, um eine echte Präzisionsmedizin umzusetzen.

\section{Finanzierung der Studie}

Wir danken dem italienischen Gesundheitsministerium (5X1000 Finanzmittel; CO-2016-02361470) und der Compagnia di San Paolo (2017-0529), die unsere aktuelle Forschung, die auf die Identifizierung prognostischer und prädiktiver Marker für die Immuntherapie ausgerichtet ist, finanziell unterstützt.

\section{Interessenskonflikte}

C.G.: Honorare von Astra Zeneca, Bristol Meyer Squibb, Boehringer Ingelheim, MSD, Roche; G.R.: Honorare von Roche, AMGEN, Novartis.

\section{Lizenzangabe}

Rossi G, Russo A, Tagliamento M, Tuzi A, Nigro O, Vallome G, Sini C, Grassi M, Dal Bello MG, Coco S, Longo L, Zullo L, Tanda ET, Dellepiane C, Pronzato P, Genova C: Precision Medicine for NSCLC in the Era of Immunotherapy: New Biomarkers to Select the Most Suitable Treatment or the Most Suitable Patient. Cancers (Basel). 2020;12(5):1125 (DOI:10.3390/ cancers12051125). ${ }^{\circledR} 2020$ by the authors. Licensee MDPI, Basel, Switzerland (Übersetzung), lizensiert unter CC BY 4.0 (https://creativecommons. org/licenses/by/4.0/deed.de).

\section{Literatur}

Die Literatur ist unter www.karger.com/Article/Fulltext/511444 abrufbar. 